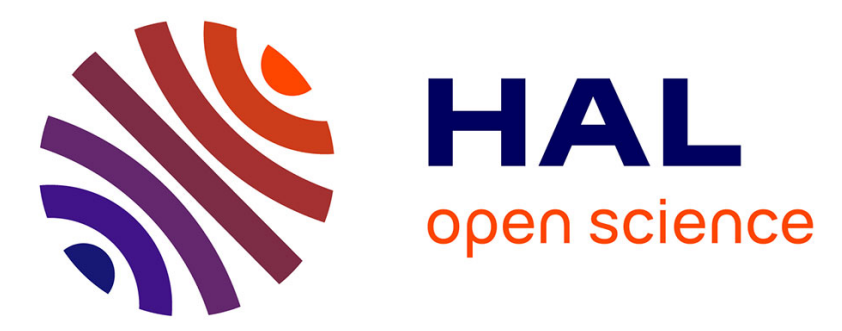

\title{
Properties and applications of surface wave produced plasmas
}

\author{
M. Moisan, C.M. Ferreira, Y. Hajlaoui, Dominique Henry, J. Hubert, R. \\ Pantel, André Ricard, Z. Zakrzewski
}

\section{- To cite this version:}

M. Moisan, C.M. Ferreira, Y. Hajlaoui, Dominique Henry, J. Hubert, et al.. Properties and applications of surface wave produced plasmas. Revue de Physique Appliquée, 1982, 17 (11), pp.707-727. 10.1051/rphysap:019820017011070700 . jpa-00245049

\section{HAL Id: jpa-00245049 https://hal.science/jpa-00245049}

Submitted on 1 Jan 1982

HAL is a multi-disciplinary open access archive for the deposit and dissemination of scientific research documents, whether they are published or not. The documents may come from teaching and research institutions in France or abroad, or from public or private research centers.
L'archive ouverte pluridisciplinaire HAL, est destinée au dépôt et à la diffusion de documents scientifiques de niveau recherche, publiés ou non, émanant des établissements d'enseignement et de recherche français ou étrangers, des laboratoires publics ou privés. 
Classification

Physics Abstracts

52.75

\title{
Properties and applications of surface wave produced plasmas $\left({ }^{*}\right)$
}

\author{
M. Moisan, C. M. Ferreira $\left({ }^{1}\right)$, Y. Hajlaoui $\left({ }^{2}\right)$, D. Henry $\left({ }^{3}\right)$, J. Hubert $\left({ }^{4}\right)$, \\ R. Pantel $\left({ }^{5}\right)$, A. Ricard $\left({ }^{6}\right)$ and Z. Zakrzewski ( $\left.{ }^{7}\right)$ \\ Département de Physique, Université de Montréal, Montréal, Québec H3C 3J7
}

(Reçu le 15 décembre 1981, révisé le 8 juillet 1982, accepté le 3 août 1982)

\begin{abstract}
Résumé. - De longues colonnes cylindriques de plasma, stables, calmes et reproductibles, peuvent être obtenues grâce à la propagation d'ondes de surface électromagnétiques. La fréquence de ces ondes est de l'ordre de la fréquence plasma-électronique et elle se situe dans le domaine $(\simeq 300-4000 \mathrm{MHz})$ des hyperfréquences $(\mathrm{HF})$ où il est relativement facile de se procurer, à des coûts raisonnables, le niveau de puissance HF nécessaire. De plus, ces ondes peuvent être excitées très efficacement en recourant à des dispositifs appropriés, comme le surfatron. Les plasmas ainsi obtenus peuvent, dans certains cas, remplacer avantageusement les plasmas de colonnes positives en courant continu.

Cet article de revue présente d'abord les propriétés des colonnes de plasma entretenues par l'onde de surface à symétrie azimutale. On s'intéresse notamment aux distributions radiale et axiale de la densité électronique ainsi qu'aux distributions radiales de la densité des atomes excités (radiatifs et métastables). On donne ensuite un résumé de quelques applications déjà réalisées ainsi que des indications sur d'autres applications possibles.
\end{abstract}

\begin{abstract}
Long quiescent, stable and reproducible cylindrical plasma columns can be obtained as a result of the propagation of electromagnetic surface waves. The frequency of these waves is of the order of the electronplasma frequency and it lies in that part $(\simeq 300-4000 \mathrm{MHz})$ of the microwave spectrum where power generators with large enough output powers are readily available, at reasonable cost. Moreover, these waves can be excited very efficiently by using appropriate launching structures such as the surfatron. Such plasmas can, in certain instances, advantageously replace the positive column of DC discharges.

This paper reviews the properties of the plasma columns sustained by the azimuthally symmetric surface wave. Special attention is given to the radial and axial electron density distributions, as well as to the radial density distributions of excited (radiative and metastable) atoms. Some demonstrated applications as well as further potential applications are also presented.
\end{abstract}

$\left(^{*}\right)$ Presented in part at the Conference on Surface Waves in Plasmas (Blagoevgrad, Bulgaria, Oct. 1981).

( $\left.{ }^{1}\right)$ Permanent address : Centro de Electrodinámica da Universidade Técnica de Lisboa, Instituto Superior Técnico, Lisboa 1000, Portugal.

$\left({ }^{2}\right)$ Centre de recherches en physique de l'environnement terrestre et planétaire (CRPE)-CNET, 45045 Orléans Cedex, France.

$\left({ }^{3}\right)$ Centre de recherches en physique de l'environnement terrestre et planétaire (CRPE)-CNET, 45045 Orléans Cedex, France. Now with CNET, BP 42, 38240 Meylan, France.

$\left({ }^{4}\right)$ Permanent address : Département de chimie, Université de Montréal, Montréal, Québec, H3C $3 J 7$.

$\left({ }^{5}\right)$ Now with CNET, BP 42, 38240 Meylan, France.

$\left({ }^{6}\right)$ Permanent address : Laboratoire de physique des plasmas, Université Paris-Sud, 91405 Orsay, France.

$\left({ }^{7}\right)$ Permanent address : Polish Academy of Sciences, IMP-PAN, 80-952 Gdansk, Poland.
1. Introduction. - It is well known that it is possible to use microwave energy to sustain a plasma. The electromagnetic energy is transmitted to the plasma particles via the microwave electric field. This field accelerates the electrons that dissipate the microwave energy through elastic and inelastic collisions with neutral atoms. The ways in which the electric field can be imposed on the plasma are numerous. For example, it can be applied within an electromagnetic resonant cavity [1, 2] or using bounded plasma resonances $[3,4]$, both methods enhancing the electric field intensity. It can also come from a wave travelling along the plasma column. A travelling wave can be supported by a slow wave structure that accompanies the plasma column [5] or it can propagate within a waveguide that encloses the plasma column [6] ; it can also use the plasma column 
as the sole propagating medium : such is the case with surface wave produced plasmas [7].

Electromagnetic surface waves, sometimes called radio surface waves, have long been the subject of intensive works [8]. They date back to 1901 in connection with Marconi's first transmission across the Atlantic Ocean and its tentative explanation in terms of a wave being guided along the earth surface. As for plasma surface waves specifically, they were observed for the first time in 1958 by Trivelpiece [9], as waves propagating along positive column plasmas. The power level used at that time was low enough so that the parameters of the DC plasma column were not affected by the fields of the surface wave propagating along it. A complete review on the experiments and on the theories concerning these non-ionizing plasma surface waves can be found, respectively, in [10] and [11]. In 1974, patents applications were filed [12] concerning surface wave launchers (later on called surfatron and surfaguide) that enable to produce long plasma columns with microwave energy. These results were then published in [13]. The object of this paper is to review the work done since then concerning surface wave produced plasmas.

A surface wave produced plasma column, as already mentioned, is a plasma sustained by the propagation of an electromagnetic surface wave that uses the plasma column as its sole propagating medium. Such a propagation can be considered to result from a periodic interchange of the energy in the wave field with the ordered kinetic energy of electrons. The wave damps as it propagates since it transfers some of its energy to the plasma at each point along the column. This paper will consider only the stationary regime of wave propagation, i.e., we do not deal with the transient phenomena occurring as the microwave power is initially applied, when there is no plasma yet [14].

It is interesting to point out that, for a given azi-

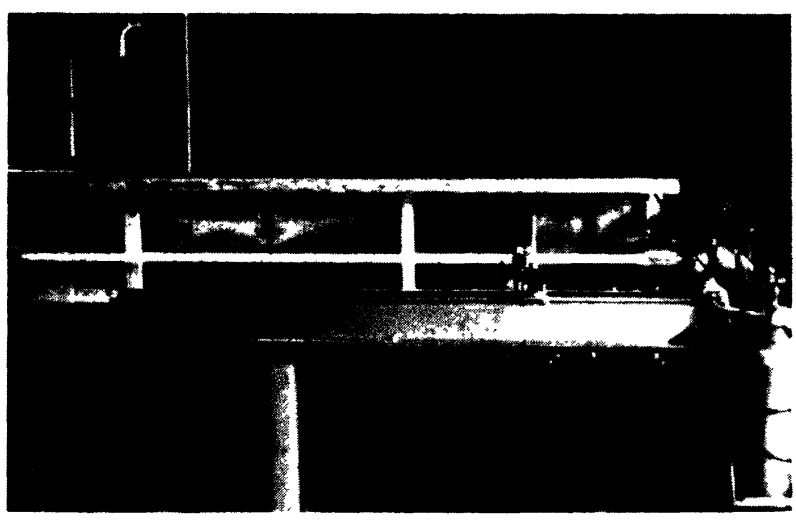

Fig. 1. - Photograph of a surface wave produced plasma column obtained at $\mathbf{4 0}$ mtorr of argon in a $25 \mathrm{~mm}$ i.d. pyrex tube with $80 \mathrm{~W}$ of microwave power at $500 \mathrm{MHz}$. The plasma column is 1.8 metre long. The wave launcher (surfatron) is located on the far right side of the column : it is about $70 \mathrm{~mm}$ long. muthal wave mode, the properties of the surface wave launched are independent of the launcher characteristics : this means that it is possible to study such plasma columns without referring to any specific launcher.

Before going into theoretical and experimental details, we present an overall physical view of this type of plasma. Figure 1 shows the plasma column obtained at 40 mtorr of argon in a $25 \mathrm{~mm}$ i.d. tube with $80 \mathrm{~W}$ of microwave power at $500 \mathrm{MHz}$ [13]. The column is 1.8 metre long. Note that the wave launcher (surfatron [15]) is small and localized compared to the extent of the plasma column it produces. Figure 2 shows the cross-sectional average value of the electron density measured as a function of axial position. Except for a region $\left({ }^{1}\right)$ close to the launcher, the electron density decreases approximately linearly with the distance from the launcher exit (indicated by a circle in figure 2), until a cut-off value is reached (indicated by an arrow in figure 2), after which the density drops abruptly to zero over a few centimetres only. When the microwave power absorbed by the launcher is increased $(130 \mathrm{~W}$ instead of $100 \mathrm{~W}$ in figure 2), the column length increases. A close look at figure 2 shows that the plasma column obtained at $130 \mathrm{~W}$ is made up of the plasma column that is

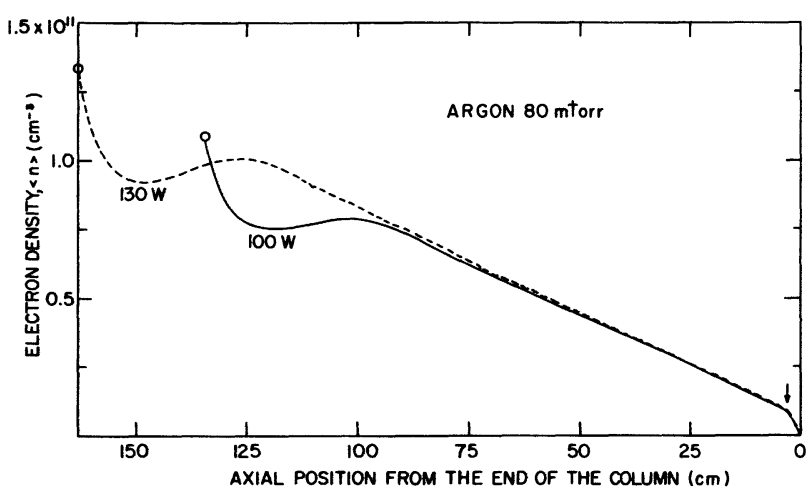

Fig. 2. - Measured cross-sectional average value of the electron density, $\langle n\rangle$, along a surface wave produced plasma column as a function of axial position from the end of the column, for two different absorbed microwave power values to the launcher. The wave frequency is $360 \mathrm{MHz}$ and the tube diameter is $25 \mathrm{~mm}$. The launcher position is indicated by a circle. The irregular behaviour of the electron density distribution in the immediate vicinity of the launcher is connected with launching problems (footnote 1). The arrow on the far right side of the figure indicates the cut-off point of the plasma column (footnote 4). (From [29].)

( $\left.{ }^{1}\right)$ The peculiar axial density variation over this interval is connected with the presence of a particularly high level of radiation field (space wave) near the launcher. This field becomes negligible compared to that of the surface wave at a distance from the launcher exit that ranges from about $\lambda_{0} / 4$ to $\lambda_{0} / 2\left(\lambda_{0}\right.$ is the vacuum wavelength of the microwave signal), depending on the wavelength value of the surface wave [16]. 
observed at $100 \mathrm{~W}$, plus an additional length of plasma which is added on the high electron density side of the former column. At the same time, one notes that the slope of the axial electron density distribution remains the same at all points along the column, whatever the microwave power. It is thus more meaningful to reference the axial position in such a plasma with respect to the end of the column.

The surface wave produced plasma columns are in fact of two possible types. The first type is observed at reduced pressures, typically below 20 torr in argon, and it corresponds to the condition $v<\omega$ ( $v$ is the effective average electron-neutral collision frequency for momentum transfer and $\omega$ is the wave angular frequency). The wave propagation, in this case, is obviously akin to that along a dielectric rod (with a negative permittivity value). The second type is obtained at higher pressures, typically of the order of one atmosphere, and it is characterized by the fact that, contrary to reduced pressure plasmas, the plasma does not fill the entire tube cross section. It is self-constricted to a diameter of the order of one $\mathrm{mm}$. This filament-like plasma is usually located on the axis of the glass (fused silica) tube that contains it. Column lengths up to $50 \mathrm{~cm}$ have been reported in argon with a microwave power of $700 \mathrm{~W}$ [17]. This plasma satisfies the condition $v>\omega$ and the wave resembles the one obtained for propagation along a conducting wire coated with a dielectric (Goubau's line) [18].

2. Theoretical radial variation of the wave fields, density of electrons, and excited atoms. - 2.1 RADIAL VARIATION OF THE WAVE FIELDS AND DENSITY OF ELECTRONS. - The radial variation of the wave fields inside the plasma as well as that of the electron density have not yet been determined experimentally. It is thus important to gather as much theoretical indications as possible.

Though plasma columns can also be sustained by dipolar surface waves [19], we only consider the (theoretically) simpler $\left({ }^{2}\right)$ case of azimuthal symmetry. Owing to boundary conditions, such waves, when propagating along a plasma column without an external magnetic field, can only be TM waves, whose non-zero electric and magnetic field components reduce to $E_{z}, E_{r}$ and $H_{\phi}$ (cylindrical coordinates, where $z$ is the plasma column axis). The radial variation of these components is easily expressed in terms of modified Bessel functions provided the electron density is assumed radially uniform. Figure 3 shows the calculated intensity, as a function of radial position, of the radial and axial electric field components $\left|E_{r}(r)\right|$ and $\left|E_{z}(r)\right|$ of the azimuthally sym-

$\left({ }^{2}\right)$ For the dipolar mode and all higher order azimuthal modes, the calculation requires the consideration of both TM and TE components in the solution, since these modes are hybrid.

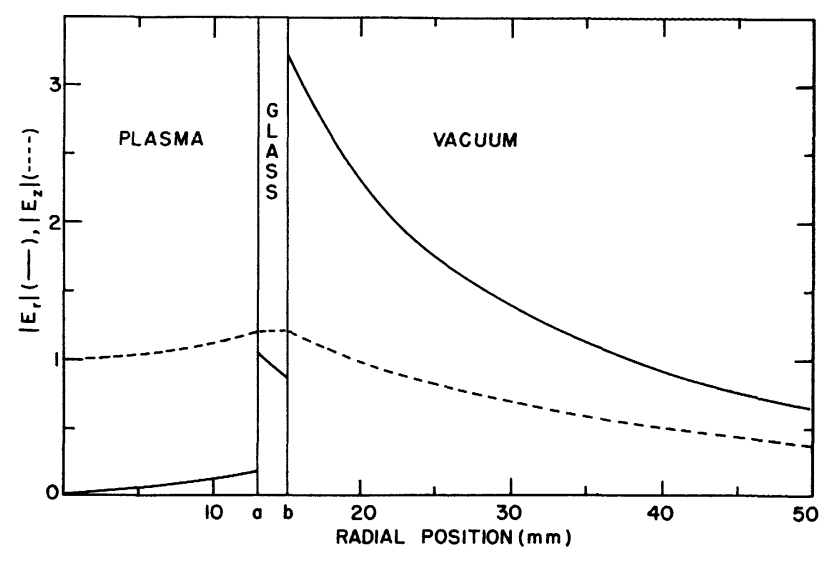

Fig. 3. - Calculated intensity, as a function of radial position, of the radial and axial electric field components, $\left|E_{r}(r)\right|$ and $\left|E_{z}(r)\right|$, of an azimuthally symmetrical surface wave propagating over a cylindrical plasma column enclosed in a glass tube surrounded by vacuum. The glass tube relative permittivity is 3.8 , with inside and outside radii, respectively, $a$ and $b$. The wave frequency is $600 \mathrm{MHz}$. The ratio of the electron-plasma frequency over the wave frequency, $f_{\text {pe }} / f_{0}=5$. The intensities are normalized by requiring $\left|E_{z}(0)\right|=1$. (From [10].)

metric surface wave propagating over a cylindrical plasma column. Note that, in the plasma, the predominant electric field component is clearly $E_{z}$, while outside the plasma tube, in air, it is $E_{r}$.

The assumption of a homogeneous plasma proves adequate to determine the wave dispersion curve, provided $\beta a<1$ ( $\beta$ is the surface wave wavenumber and $a$ is the plasma radius), i.e., when the wave does not « see " the radial inhomogeneities [20]. However, when it comes to matching experimental data concerning radially dependent quantities such as the radiative and metastable atom densities, this assumption is inaccurate, since these quantities are observed to depend closely on the electric field radial profile. The problem of calculating the exact electric field profile is that of solving a differential equation for $E_{z}(r)$ that depends on the electron density radial profile. Unfortunately, this density radial profile is not known a priori and, actually, it depends on the electric field profile. This is thus a self-consistent problem. This problem was first solved [21] in a very approximate way : calculations of the electron density radial profile were made, assuming ambipolar diffusion with an electron temperature $T_{\mathrm{e}}$ independent of the radius and considering a variety of possible surface wave electric field profiles. It was found that the density profile that results could be approximately represented by a $J_{0}(\mu r / a)$ dependence $\left(J_{0}\right.$ is the zeroorder Bessel function of the first kind) with $\mu<2.4$ : the radial distribution of electrons in surface wave plasmas thus appears to be slightly flatter than in DC positive columns (under ambipolar diffusion conditions) where $\mu \simeq 2.4$. On the other hand, starting the calculations the other way around, 
i.e., assuming a density distribution of the form $J_{0}(\mu r / a)$ and considering various values of $\mu<2.4$ $\left(J_{0}(\mu)\right.$ is the density value at the tube wall), it is found that the resulting radial electric field component $E_{n}$ contrary to the uniform plasma case, takes on a non-negligible value close to the tube wall, this value increasing with the electron density gradient.

More recently, Ferreira [22] directly solved this self-consistent problem using two-moment equations for both electrons and ions, the equations for the wave electric field, and a power balance equation for the electrons. In this way, the theory accounts for the radial variation of the electron temperature and the ionization rate and no assumptions are necessary concerning the values of the plasma density at the boundary, the latter following from the theory itself. This fact is particularly important for the treatment of low pressure plasma columns, as it is observed that, in this case, the plasma density does not fall to zero at the plasma boundary (i.e., in practice, at $r \simeq a$, neglecting the sheath thickness), unlike what is usually assumed in the framework of Schottky's ambipolar diffusion theory. The electron temperature and the ionization rate increase with radius is associated with the corresponding increase of the wave electric field intensity. Some results of Ferreira's calculations are presented in figures 4 to 8 . Figure 4 shows some typical calculated radial distributions of the electron temperature for a constant absorbed power per unit length of $30 \mathrm{~W} / \mathrm{m}$ and for different values of the gas pressure. It is seen that the

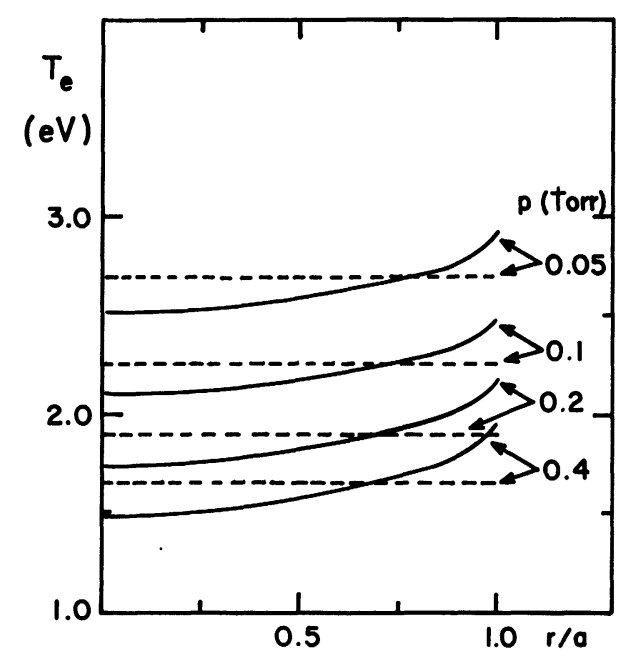

Fig. 4. - Calculated radial distribution of the electron temperature $T_{\mathrm{e}}$ in an azimuthally symmetrical surface wave produced plasma, for various gas pressures $p$ in argon. The plasma diameter is $25 \mathrm{~mm}$, the wave frequency is $600 \mathrm{MHz}$ and the total power absorbed per unit length is $30 \mathrm{Wm}^{-1}$. The corresponding values of the average electron density $\langle n\rangle$ are : $8 \times 10^{10} \mathrm{~cm}^{-3}$ for $p=0.05$ torr, $1.3 \times 10^{11} \mathrm{~cm}^{-3}$ for 0.1 torr, $2 \times 10^{11} \mathrm{~cm}^{-3}$ for 0.2 torr, $3.4 \times 10^{11} \mathrm{~cm}^{-3}$ for 0.4 torr. The dashed lines are for an isothermal DC positive column plasma of the same diameter, as calculated from the two-moment theory.

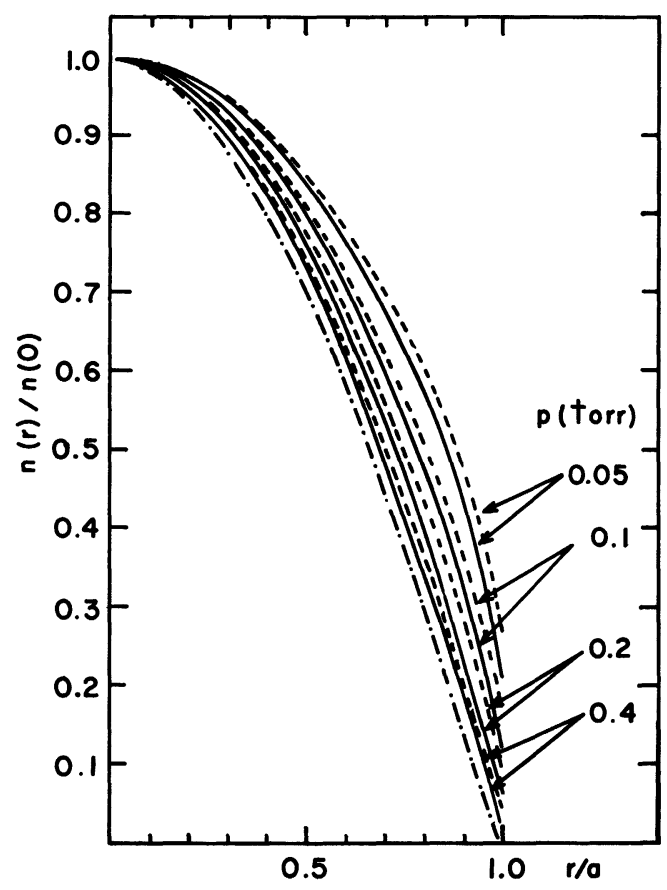

Fig. 5. - Calculated electron density radial profiles in a surface wave produced plasma, for a given average electron density value $\langle n\rangle=10^{11} \mathrm{~cm}^{-3}$ and various argon gas pressures $p$. The dashed lines are for an isothermal DC positive column plasma of the same diameter, as calculated from the two-moment theory. The dot-dash line is for $J_{0}(2.4 r / a)$. The other conditions are those of figure 4.

electron temperature increases with radius. Figures 5 and 6 represent calculated radial profiles of electron density, for a fixed value of the cross-sectional average electron density $\langle n\rangle$ and various gas pressures, and for a fixed gas pressure and various average electron density values. Also shown in figures 4 to 6 , as dashed lines, are the results obtained in the case of an isothermal DC positive column plasma using also the two-moment theory. As concerns the electron temperature, as could be expected, the values obtained in both cases are comparable. However, it is seen that the surface wave produced plasma column can be maintained against particle losses with a value of the electron temperature at the axis that is somewhat lower than that in the isothermal case, owing to the increase of the temperature and the ionization rate with radius. From figure 5 , it can be concluded that the radial profiles of electron density in the surface wave plasma are quite comparable to those of the isothermal column, for various gas pressures. This is true provided sufficiently low values of the average electron density are considered, i.e., typically below $10^{11}$ electrons $\mathrm{cm}^{-3}$. In fact, as shown in figure 6 , for larger values of the average electron density, the surface wave plasma profiles become flatter in the region close to the axis. This result may be understood by noting that, for a given gas pressure, the radial profile of the wave total electric field intensity becomes 


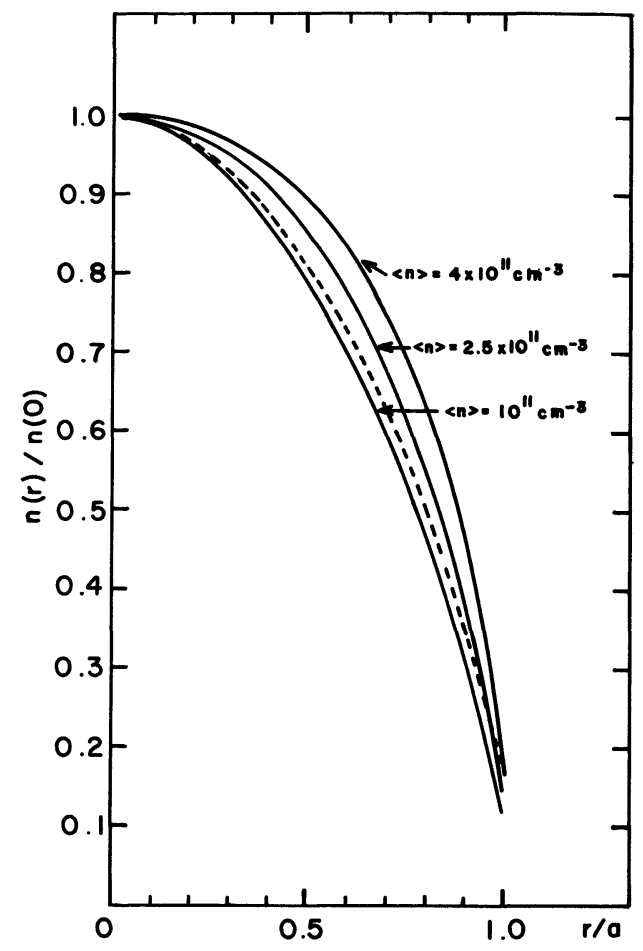

Fig. 6. - Calculated electron density radial profiles in a surface wave produced plasma, for a given argon gas pressure of 0.1 torr and various average electron density values $\langle n\rangle$. The dashed line is for an isothermal DC positive column plasma, as calculated from the two-moment theory. The other conditions are those of figure 4. (From Ferreira [22].)

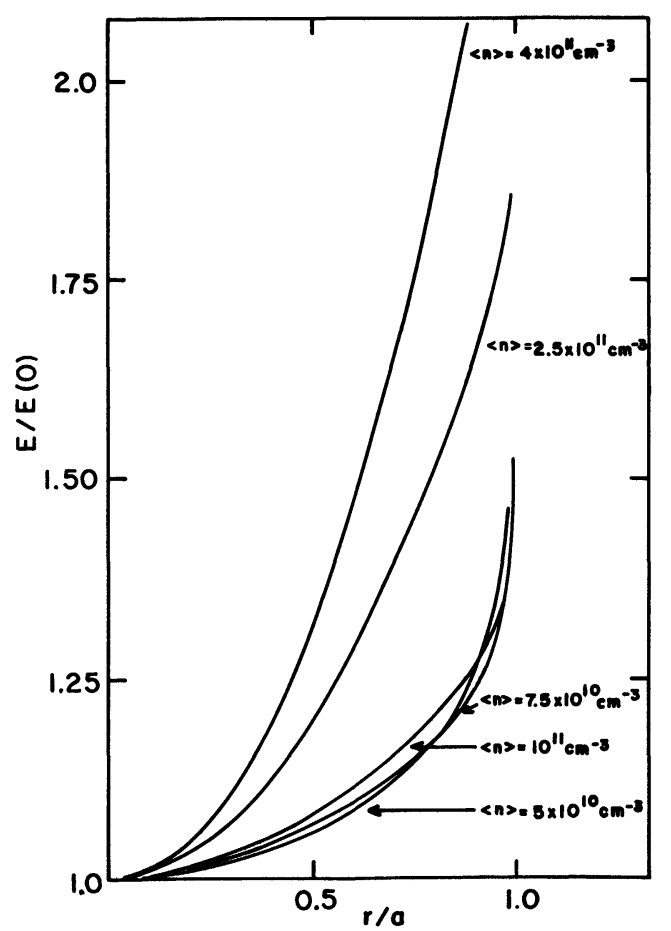

Fig. 7. - Calculated radial profile of the surface wave total electric field intensity in a surface wave produced plasma, for an argon gas pressure of 0.1 torr and various values of the average electron density $\langle n\rangle$. The values of the electric field intensity are normalized at the axis. The other conditions are those of figure 4. (From the self-consistent model of Ferreira [22].)

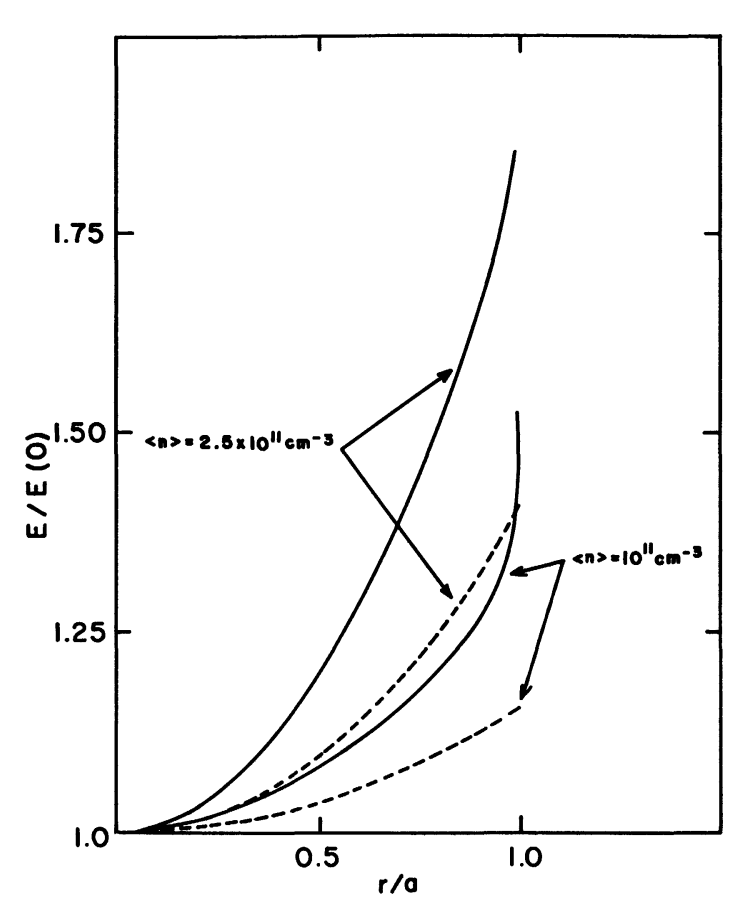

Fig. 8. - Calculated radial profiles of the surface wave total electric field intensity in the plasma, for an argon gas pressure of 0.1 torr and for two values of the average electron density, $\langle n\rangle$. The dashed line is for a homogeneous plasma and the full line is from the self-consistent model of Ferreira [22].

steeper with increasing average electron density, as illustrated in figure 7. Figure 8 compares, for two values of the average electron density, the calculated radial profiles of the total electric field intensity obtained from Ferreira's self-consistent (inhomogeneous) model with those calculated assuming the plasma to be radially homogeneous. One notes that, for a given average electron density value, the electric field profiles from the self-consistent model are steeper than those from the homogeneous model.

2.2 Radial VARIATION OF EXCITED ATOMS. - As a first approximation, it can be assumed that the power absorbed by the electrons from the wave electric field is locally dissipated by electron-neutral atom collisions, i.e., heat conduction can be neglected (note that the radial gradients of the electron temperature in figure 4 are small). In this case, the power balance equation for electrons may be written [23] :

$$
\begin{aligned}
\left\{\frac{e^{2}}{m}\left(\frac{v}{\omega^{2}+v^{2}}\right)\right\} & E^{2}(r) \simeq v_{\mathrm{i}} e V_{\mathrm{i}}+ \\
& +\sum_{\mathrm{j}} v_{\mathrm{j}} e V_{\mathrm{j}}+3(m / M) v \kappa T_{\mathrm{e}},
\end{aligned}
$$

where $v_{i}$ and $V_{i}$ are, respectively, the ionization frequency and the ionization potential, and $v_{\mathbf{j}}$ is the excitation frequency to level $\mathrm{j}$ of potential energy $V_{\mathrm{j}}$; $e$ and $m$ are, respectively, the electron charge and mass values, $M$ is the atom mass, $\kappa$ is the Boltzmann 
constant, $E$ is the intensity of the wave (total) electric field, and $v$ is an effective electron-neutral collision frequency for momentum transfer [22].

For the low-pressure range of interest here (typically $<1$ torr), the values of the electron temperature are sufficiently high so that the inelastic losses are dominant as compared to the elastic ones; hence, the term $3(m / M) v \kappa T_{\mathrm{e}}$ can be neglected in equation (1). In this case, equation (1) shows that the total power loss rate by inelastic collisions is proportional to $E^{2}$, i.e., $v_{\mathrm{i}} V_{\mathrm{i}}+\sum_{\mathrm{j}} v_{\mathrm{j}} V_{\mathrm{j}} \propto E^{2}$. As a first approximation, it can be assumed that the individual inelastic collision frequencies are roughly proportional to $E^{2}$, i.e.,

$$
\begin{aligned}
& v_{\mathrm{i}}=A_{\mathrm{i}} E^{2}(r), \\
& v_{\mathrm{j}}=A_{\mathrm{j}} E^{2}(r),
\end{aligned}
$$

where $A_{\mathrm{i}}$ and $A_{\mathrm{j}}$ are constant independent of radius. These expressions are useful for practical purposes. For instance, they can be used for approximate calculations of the radial profiles of electron density and excited atom population density. However, it must be borne in mind that they are not exact and that to obtain an accurate relation would require equation (1) to be solved, using an appropriate set of electron-neutral inelastic collision cross sections. Using linear approximations for these cross sections near their threshold values and assuming a Maxwellian electron energy distribution, a detailed analysis for argon has shown [22] that, in general, one can write $v_{\mathrm{j}}=A_{\mathrm{j}} E^{K_{\mathrm{j}}}$, where $K_{\mathrm{j}}$ is a real number that increases with the value of $V_{\mathrm{j}}$. In particular, for the ionization frequency, one obtains $v_{\mathrm{i}}=A_{\mathrm{i}} E^{2.9}$. These results do not differ significantly from those expressed by equation (2), which can, thus, be retained for simplicity.

3. Experimental evidence of surface wave propagation. - Wave interferograms have been recorded along these microwave-produced plasma columns [7, 24]. They indicate that a purely travelling wave is propagating away from the launcher. With reduced pressure plasma $(v<\omega)$, it has been shown that, for wave frequencies in the range $300-600 \mathrm{MHz}$, the calculated surface wave linear phase diagram $\left({ }^{3}\right)$ $\omega / \omega_{\mathrm{pe}} v s . \quad \beta a\left(\omega_{\mathrm{pe}}\right.$ is the electron-plasma angular frequency) is satisfactorily verified (Fig. 9; see also [7]). Figure 10 presents the measured radial variation of $\left|E_{r}(r)\right|^{2}$ outside the plasma tube, starting from the tube edge. The points in figure 10 represent fitted values obtained, assuming that $E_{r}(r)$ is given by the expression (homogeneous plasma) :

$$
E_{r}(r)=\frac{A \beta}{\left(\beta^{2}-\beta_{0}^{2}\right)^{1 / 2}} K_{1}\left[\left(\beta^{2}-\beta_{0}^{2}\right)^{1 / 2} r\right],
$$

$\left({ }^{3}\right)$ The term phase diagram is used to emphasize that in the dispersion relation, the wave frequency is kept fixed while the electron plasma frequency is varied, as opposed to a dispersion diagram $\left(\beta=\frac{2 \pi}{\lambda}\right)$.

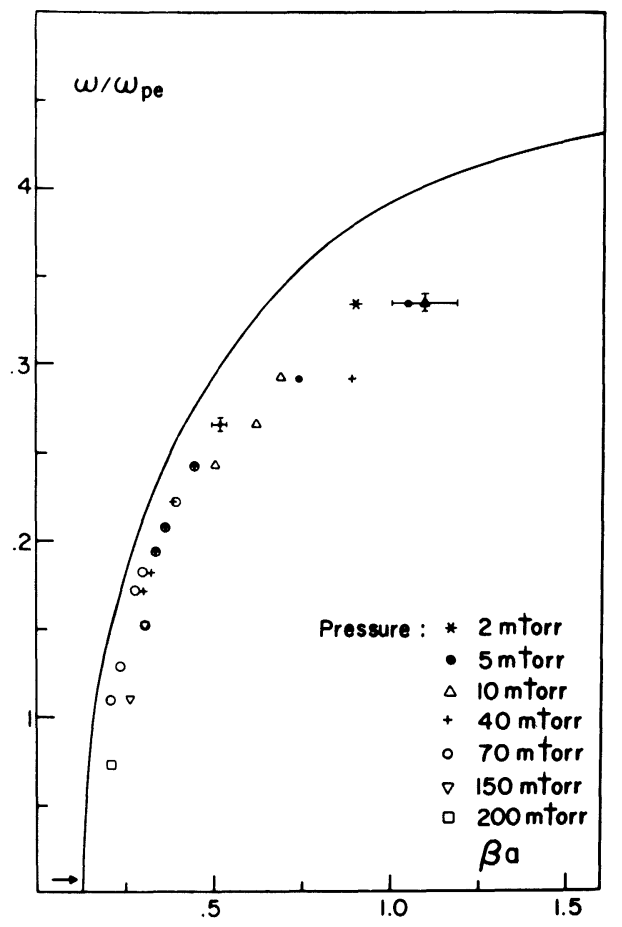

Fig. 9. - Phase diagram obtained from an argon surface wave produced plasma column at low pressures (first type plasma). The surface wave frequency $\omega / 2 \pi$ is $500 \mathrm{MHz}$. The glass tube relative permittivity is 4.52 , with inner and outer diameters, respectively, 25 and $30 \mathrm{~mm}$. The arrow located near the origin indicates approximately the domain of $\omega / \omega_{\mathrm{pe}}\left(\omega_{\mathrm{pe}}\right.$ is the electron-plasma angular frequency) corresponding to the filamentary plasma at atmospheric pressure (second type plasma). The full line is calculated from the full set of Maxwell equations, assuming a homogeneous cold plasma.

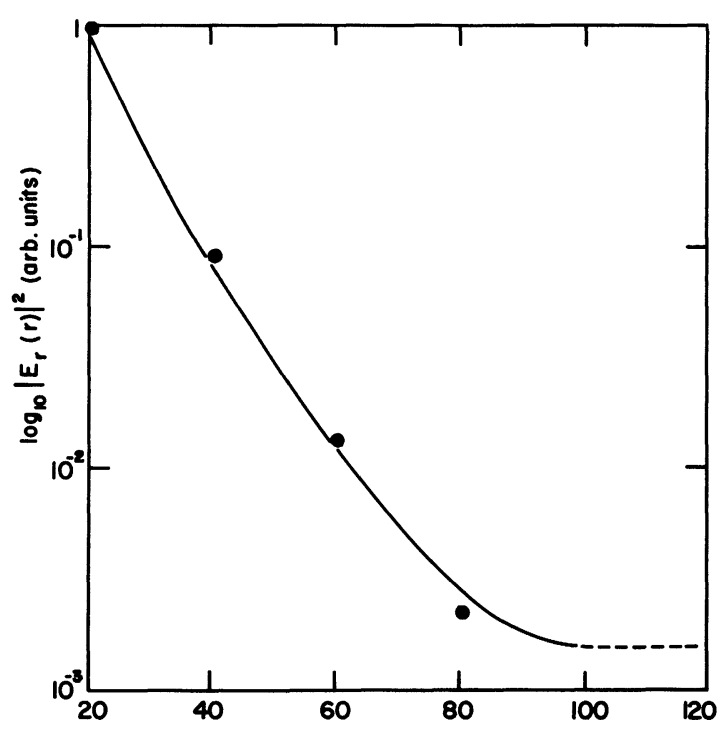

Fig. 10. - The full line is a recording of $\log _{10}\left|E_{r}(r)\right|^{2}$ versus radial position, as measured outside the plasma tube with a radially oriented electric antenna. The position $r \simeq 20 \mathrm{~mm}$ corresponds to the tip of the antenna almost touching the glass tube. The points are fitted values, assuming equation (3) for $E_{r}(r)$, that yield $\beta=36.3 \mathrm{~m}^{-1}$. From the cold plasma phase diagram, we deduce that this $\beta$ value corresponds to $f_{\mathrm{pe}} / f_{0}=3.45$. 
where $A$ is a constant, $\beta_{0}=\omega / c$ (c, the speed of light in vacuum), and $K_{1}$ is the first order modified Bessel function of the second kind : the adjustment parameter is $\beta$. From this value of $\beta$, assuming the calculated phase diagram to be correct, one can obtain the average electron plasma frequency value $f_{\overline{\mathbf{p e}}}=\omega_{\overline{\mathbf{p e}}} / 2 \pi$, with

$$
\omega_{\overline{\mathrm{pe}}}=\left(\langle n\rangle e^{2} / m \varepsilon_{0}\right)^{1 / 2},
$$

where $\langle n\rangle$ is the cross-sectional average electron density given by :

$$
\langle n\rangle=\frac{2}{a^{2}} \int_{0}^{a} n(r) r \mathrm{~d} r
$$

and $\varepsilon_{0}$ is the permittivity of free space. Figure 10 clearly shows the exponential-like decay of the surface wave in the direction transverse to its propagation. This property of surface waves ensures that the electromagnetic (EM) radiation in the radial direction remains small, an interesting feature for applications where EM radiation must be kept to a low level.

As for the second type of surface wave produced plasmas, i.e., the one resembling a conducting wire coated with a dielectric, because of experimental reasons, dispersion measurements made up to now have been performed mainly at atmospheric pressures of about 1.5 to 3 bars. However, this filamentary plasma can also be obtained at pressures ranging typically from about 100 torr to many times the atmospheric pressures. The plasma column length observed in argon with $700 \mathrm{~W}$ of microwave power $(915 \mathrm{MHz})$ is about $500 \mathrm{~mm}$. The recorded phase velocities are typically around $70 \%$ of the speed of light, clearly indicating that we are dealing with a slow wave. At $915 \mathrm{MHz}$, we thus obtain a wave interferogram showing about one and a half wavelength. We observe that these three half-wavelength values do not differ appreciably one from the other, and that, furthermore, the wavelength value does not vary much when the tube diameter, the microwave power of the gas flow are varied. Typically, the phase velocity is in the range 0.6 to $0.75 c$. The corresponding $\beta$ values are thus all located approximately in the same region of the phase diagram, as indicated by an arrow (near the origin) in figure 9. The reason why only large phase velocities are observed with atmospheric pressure plasmas follows from the results at reduced pressures in figure 9. One sees that the largest $\beta$ values are observed at the very low pressures and that the maximum $\beta$ value obtainable at a given pressure decreases as the pressure increases. This is explained by damping calculations [24] which yield that the space damping rate increases with the collision frequency and with the wavenumber $\beta$.

3.1 EXPERIMENTALLY OBSERVED PROPERTIES OF SURFACE WAVE PLASMA COLUMNS AT REDUCED PRESSURES (FIRST TYPE PLASMA). - 3.1.1 Radial distribution of

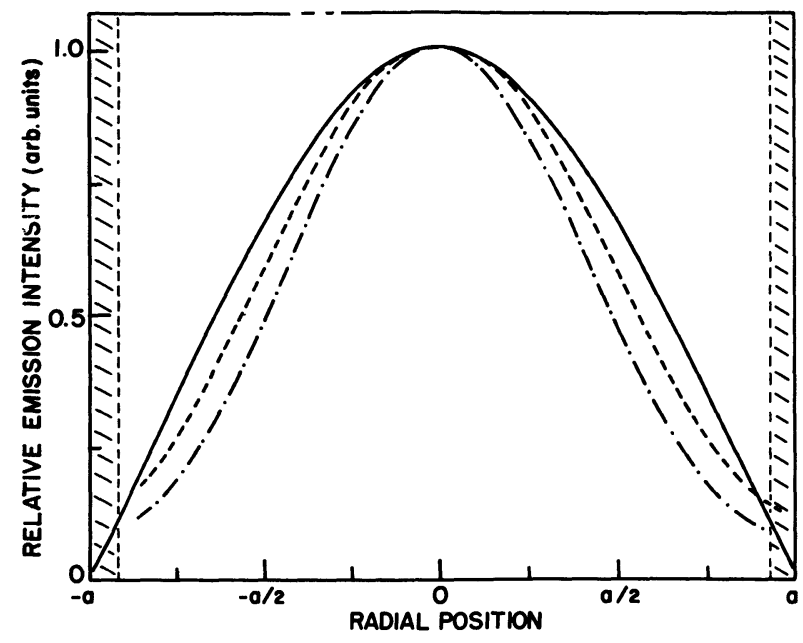

Fig. 11. - Measured relative emission intensity of the ArI $549.6 \mathrm{~nm}$ thin line as a function of radial position in the positive column of a DC glow discharge $(100 \mathrm{~mA})$, for two argon gas pressures : 0.05 torr $(---)$ and 0.1 torr $(-\cdot-\cdot)$. The plasma diameter is $26 \mathrm{~mm}$. The full line is given by $J_{0}(2.4 r / a)$. (From [23].)

excited atoms. - Figures 11 to 16 present the spontaneous emission intensity recorded as a function of radial position for a given optical transition in argon. These results are obtained by an end-on measurement method [23]. This emission intensity is locally proportional to the density of the radiative atoms in the upper level of the transition under consideration, provided the emitted line is optically thin. A measurement of the radial variation of this emission intensity thus provides a relative radial density distribution of these atoms. Figure 11, recorded in a DC positive column at two different gas pressures, shows that for such plasmas, the radial profile of radiative atoms does not deviate much from a

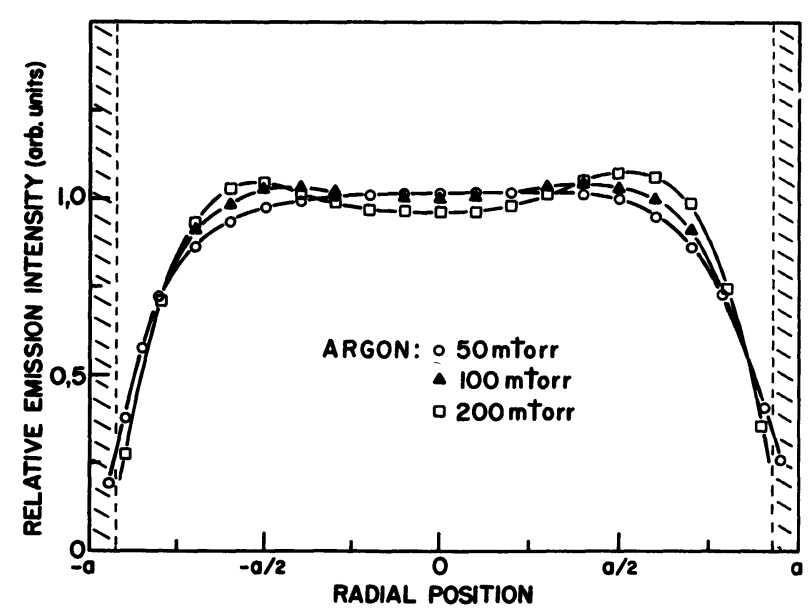

Fig. 12. - Measured relative emission intensity of the ArI $549.6 \mathrm{~nm}$ thin line as a function of radial position in a surface wave produced plasma, for three different argon gas pressures. The wave frequency is $300 \mathrm{MHz}$ and the plasma diameter is $26 \mathrm{~mm}$. (From [23].) 


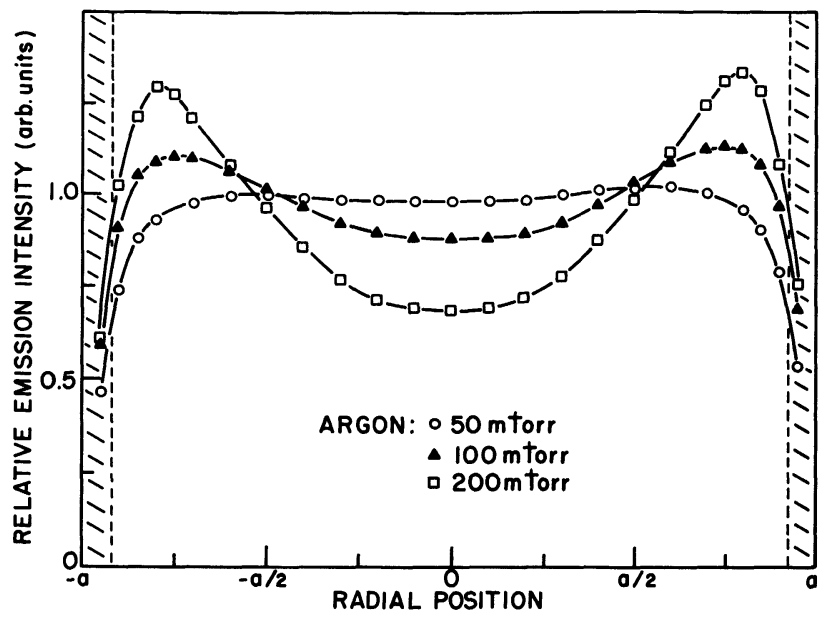

Fig. 13. - Same as in figure 12 , except that the wave frequency is $600 \mathrm{MHz}$.

$J_{0}(2.4 r / a)$ dependence. Figures 12 to 15 indicate that in surface wave produced plasma columns, the radial density profiles of these same atoms are generally quite different from those in positive columns and, further, that they vary considerably with the gas pressure, the wave frequency, and the plasma diameter [22, 23, 25]. At low enough gas pressures and wave frequencies (Fig. 12), their population density is almost flat radially. As the gas pressure or the wave frequency (in fact the electron density) or both are increased (Figs. 13 and 14), these profiles then show a relative minimum on the axis and a maximum close to the tube wall. The position of this maximum shifts toward the wall and its relative amplitude increases with increasing values of pressures or wave frequencies. The experiment also shows (Fig. 15) that increasing the plasma diameter produces a similar effect on the radial profiles of radiative atoms as does the increasing of the gas pressure or of the wave frequency. The observed dependences on the gas pressure, the wave frequency, and the plasma

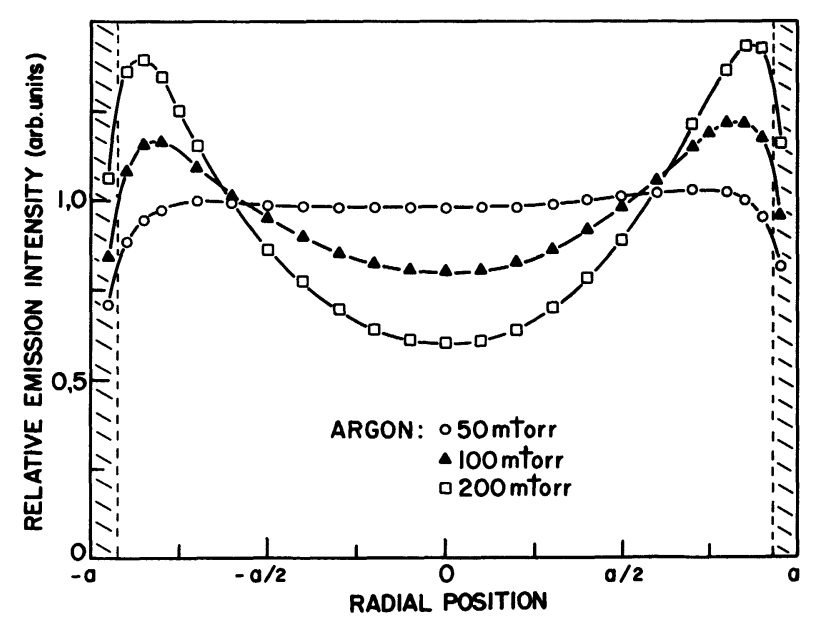

Fig. 14. - Same as in figure 12 , except that the wave frequency is $1000 \mathrm{MHz}$.

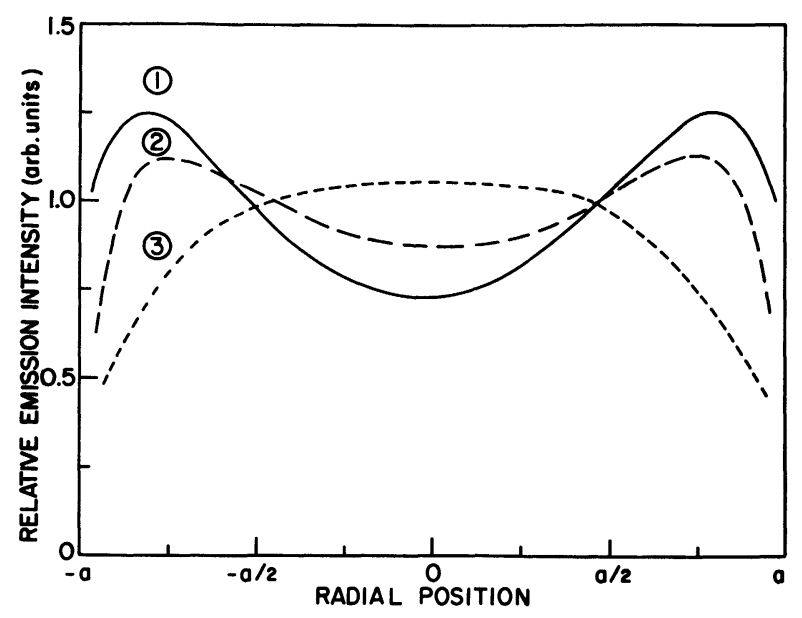

Fig. 15. - Measured relative emission intensity of the ArI $549.6 \mathrm{~nm}$ thin line as a function of radial position in a surface wave produced plasma, for three different plasma diameters : $34 \mathrm{~mm}$ (1), $26 \mathrm{~mm}$ (2), $17.5 \mathrm{~mm}$ (3). The wave frequency is $600 \mathrm{MHz}$ and the gas pressure is 0.1 torr. (From [25].)

diameter are well predicted by the models proposed in section 2.2. Similar observations regarding the radial profiles of radiative atoms in helium have been reported by Kato et al. [26] in a microwave produced plasma column which is, in our opinion, a surface wave produced plasma but which is not identified as such by these authors.

Figure 16 shows what happens to the radial profile of radiative atoms when a uniform axial DC magnetic field is applied [25]. The working conditions are set so that, with zero magnetic field value, the profile presents a deep minimum on the axis. As the electron-

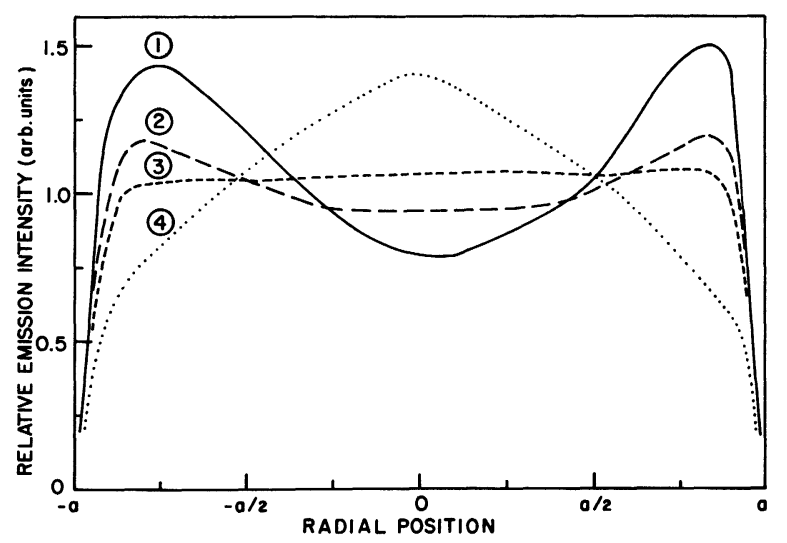

Fig. 16. - Measured relative emission intensity of the ArI $549.6 \mathrm{~nm}$ thin line as a function of radial position in a surface or volume wave produced plasma. The gas pressure is 0.2 torr, the plasma diameter is $26 \mathrm{~mm}$, and the wave frequency is $900 \mathrm{MHz}$. The plasma columns is about 1 metre long and it needs about $80 \mathrm{~W}$ of microwave power. An axial DC magnetic field can be superimposed on the plasma column : the corresponding electron-cyclotron frequencies $f_{\text {ce }}$ are : $0 \mathrm{MHz}(1), 950 \mathrm{MHz}$ (2), $1020 \mathrm{MHz}$ (3), $1290 \mathrm{MHz}$ (4). At $f_{\mathrm{ce}}=0$, the wave is a pure surface wave, while at $f_{\mathrm{ce}}=1290 \mathrm{MHz}$, it is a pure volume wave. (From [25].) 


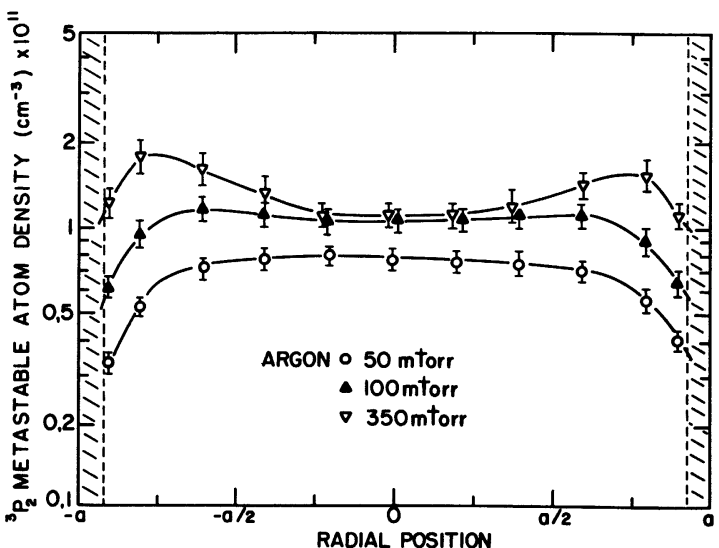

Fig. 17. - Measured density of the ${ }^{3} \mathrm{P}_{2}$ metastable atoms in argon as a function of radial position in a surface wave produced plasma, for three different gas pressures. The wave frequency is $600 \mathrm{MHz}$ and the plasma diameter is $26 \mathrm{~mm}$. The density is obtained from optical absorption on the ArI $696.5 \mathrm{~nm}$ transition. The plasma column is $200 \mathrm{~mm}$ long. (From [23].)

cyclotron frequency' is raised, the profile tends to flatten. For electron-cyclotron frequencies much larger than the wave frequency, the profile shows a maximum on the axis. These results are connected with the fact that the surface wave, with increasing electroncyclotron frequency, progressively changes and finally transforms to a volume wave, i.e., a wave having its maximum value of electric field intensity on the axis [20].

Figures 17 and 18 present the absolute density value of the ${ }^{3} \mathrm{P}_{2}$ metastable atoms and the ${ }^{1} \mathrm{P}_{1}$ resonant atoms, respectively, as a function of radial position, in a surface wave produced argon plasma (it is determined by optical absorption of the $696.5 \mathrm{~nm}$ and $750.4 \mathrm{~nm}$ lines). Compared to radiative atom density profiles in the same plasma, the metastable as well as the resonant atom density profiles are flatter (compare figures 17 and 18 with figure 13).

In DC positive columns, the maximum value of the. radial density distributions of metastable and resonant atoms is always reached on the axis. This density value goes through a maximum as a function of the discharge current $[21,28]$. As for surface wave produced plasmas, in the absence of standing wave conditions (see below), the radial position of the maximum value of these density distributions changes with the wave parameters. The maximum density value taken radially also goes through a maximum as a function of the wave parameters. The absolute maximum density values that can be observed radially in both types of plasmas are usually quite comparable. For example [28], at 100 mtorr of argon with a plasma diameter of $26 \mathrm{~mm}$, in a positive column plasma, the maximum density value for atoms in the ${ }^{3} \mathrm{P}_{2}$ state as a function of discharge current, on the axis, is about $2.3 \times 10^{11} \mathrm{~cm}^{-3}$ $(\simeq 100-200 \mathrm{~mA})$. For the surface wave produced plasma, under the same gas pressure and plasma diameter

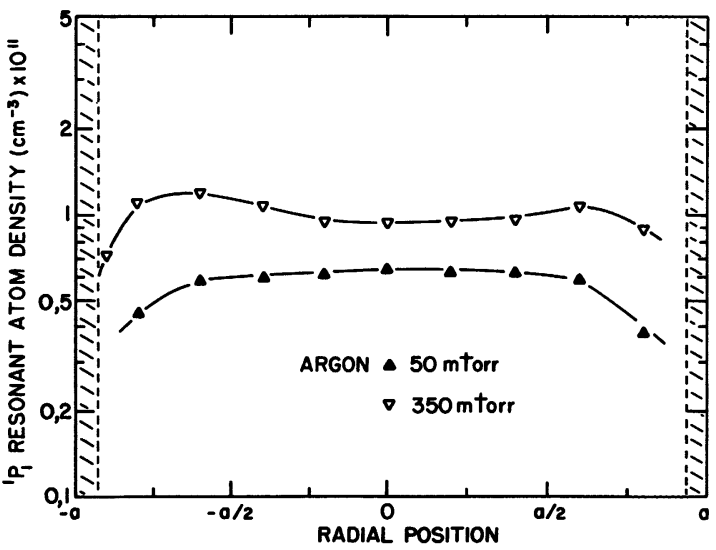

Fig. 18. - Measured density of the ${ }^{1} P_{1}$ resonant atoms in argon as a function of radial position in a surface wave produced plasma, for two gas pressures. The wave frequency is $600 \mathrm{MHz}$ and the plasma diameter $26 \mathrm{~mm}$. The density is obtained from optical absorption on the ArI $750.4 \mathrm{~nm}$ transition. The plasma column is $200 \mathrm{~mm}$ long and the microwave absorbed power is $2 \mathrm{~W}$. (From [21].)

conditions, at $600 \mathrm{MHz}$ (no wave reflections), the maximum density value for ${ }^{3} \mathrm{P}_{2}$, obtained at $r \simeq 3 / 4 a$, is about $2.1 \times 10^{11} \mathrm{~cm}^{-3}$. For some applications, like for example plasma chemistry, one important parameter is the cross-sectional average density value of these species : the larger this value, the larger the throughput. In that respect, it is not clear yet if the surface wave produced plasma under no wave reflection conditions is really superior to the $\mathrm{DC}$ positive column : more experimentation is needed. However, a clearer picture is available when the surface wave plasma is operated under multiple wave reflection

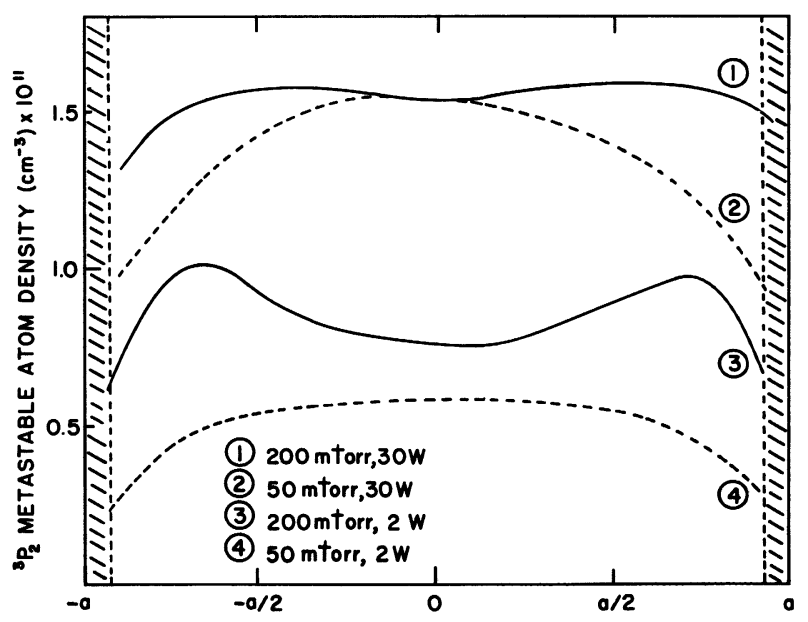

Fig. 19. - Measured density of the ${ }^{3} P_{2}$ metastable atoms in argon as a function of radial position, for two gas pressures, when the plasma column completely fills the tube length $(200 \mathrm{~mm})$ as a result of multiple reflections of the surface wave on the tube ends (curves 1 and 2). For comparison, the corresponding ${ }^{3} \mathrm{P}_{2}$ radial density distributions that are obtained when there are no reflections (pure travelling wave) are given as curves 3 and 4 . The wave frequency is $600 \mathrm{MHz}$ and the plasma diameter $26 \mathrm{~mm}$. 
conditions. A wave reflection occurs at one of the tube end when the microwave power sent by the launcher is more than what is needed for the plasma to simply reach that end. The reflected wave travels back to the launcher as the microwave power is increased, producing additional ionization and excitation along its path. For large enough microwave powers, reflections occur at both ends of the tube and, for still larger microwave powers, there will be multiple reflections. In this case, the observed radial profiles for metastable (Fig. 19) and resonant atoms appear almost completely flat $[21,25]$ and the corresponding cross-sectional average density values can be two to seven times larger than those in a positive column, at the same pressure and for the same tube diameter, for comparable electrical powers dissipated in the plasma [28].

3.1.2 Axial electron density profile. - Figure 20 presents the cross-sectional average value of the electron density, $\langle n\rangle$, measured as a function of the axial distance from the end of the column, for five different gas pressures and a wave frequency of $360 \mathrm{MHz}$. The electron density value that corresponds to the wave cut-off point $\left({ }^{4}\right)$ (indicated by an arrow in figure 20 ),

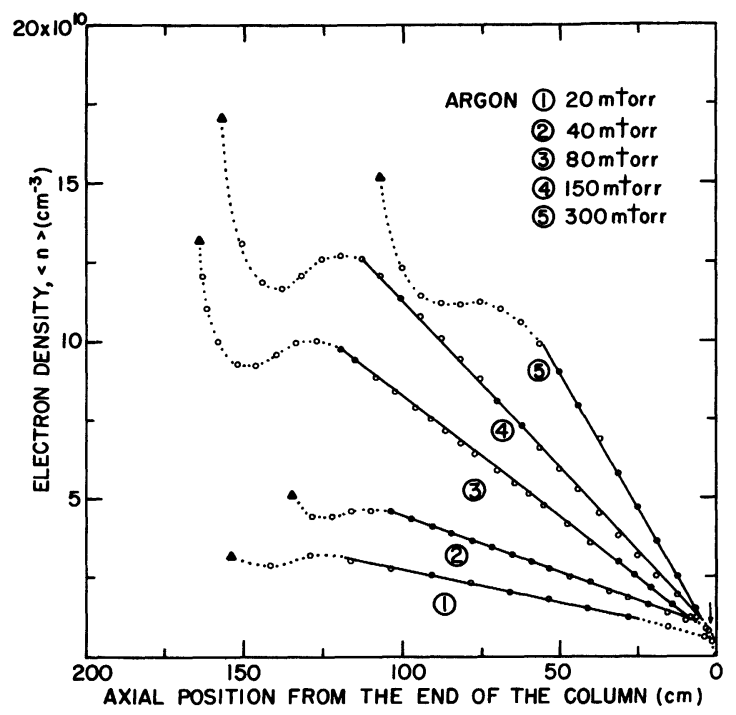

Fig. 20. - Measured distribution of the electron density $\langle n\rangle$ as a function of axial position from the end of the plasma column, for five different values of the gas pressure. The wave frequency is $360 \mathrm{MHz}$ and the plasma diameter $25 \mathrm{~mm}$. Except in the vicinity of the launcher position $(\Delta)$, where density perturbations occur in connection with the launching of the surface wave (footnote 1), straight lines can be fitted to the experimental points. From these, one can determine the electron-neutral collision frequency [29].

$\left({ }^{4}\right)$ This cut-off density can be expressed in terms of the electron-plasma frequency by the relation

$$
f_{\mathrm{pe}} \simeq \omega / 2 \pi\left(1+\varepsilon_{\mathrm{g}}\right)^{1 / 2},
$$

where $\varepsilon_{\mathrm{g}}$ is the permittivity of the glass tube. This relation is for a cold plasma, without collisions. The cut-off frequency increases with the gas pressure. just before the end of the column, is approximately the same for the five gas pressures considered (in fact, it increases slightly with pressure). With the exception of the region close to the launcher (see footnote 1), the electron density is an almost perfectly linear function of axial distance. Its gradient increases with the gas pressure. Further results would show that this gradient increases with the wave frequency and decreases with the plasma diameter [29]. All these results can be explained theoretically by a simple model that assumes that $P_{\mathrm{a}}(\Delta z)$, the wave power absorbed over an axial length $z, z+\Delta z$, is proportional to the total number of electrons over that same length [29], i.e.,

$$
\theta P_{\mathrm{a}}(\Delta z)=S \int_{z}^{z+\Delta z} n(z) \mathrm{d} z
$$

where $S$ is the plasma cross section, and $n(z)$ is the electron density as a function of axial position. The proportionality constant $\theta$ is assumed independent of the wave power and the axial position. This assumption has been verified recently by Chaker et al. [30] $\left(\theta^{-1}\right.$ is in fact the wave power absorbed by one electron). The solid lines in figure 20 are theoretical curves fitted to the experimental points to determine the electron-neutral collision frequency.

The fact that, under certains conditions, the axial gradient of electrons is important, i.e., that the two columns ends are at very different density values (typically a difference of a factor two or more over $50 \mathrm{~cm}$ ), can be a problem for applications where a homogeneous density plasma column is required. A possible way of reducing the axial density gradient, besides lowering the wave frequency and the gas pressure, or increasing the plasma diameter, is to use two launchers, one at each end of the column. These two launchers must be supplied by two microwave generators of comparable frequencies but that are not phase related, otherwise, standing waves are generated, to which correspond axial electron density variations [31]. Such a solution has been tried by us and the plasma shows a better axial density homogeneity. However, more experiments are needed to fully assess this method.

Appreciable axial density gradients, though not as large as those observed here, can be found in low pressure DC arc discharges. Considering a mercury vapour arc discharge over a pressure range of $0.5 \times$ $10^{-3}$ to $2.5 \times 10^{-2}$ torr, Agdur et al. [32] report an almost linear increase of electron density from cathode to anode. For example, with a discharge current of $1 \mathrm{~A}$ in a $13 \mathrm{~mm}$ inside diameter tube, the density value on the cathode side is $1.2 \times 10^{11} \mathrm{~cm}^{-3}$ and $2.8 \times 10^{11} \mathrm{~cm}^{-3}$ on the anode side, for a column length of $1.4 \mathrm{~m}$. The slope of this density variation increases with the discharge current and with the vapour pressure. Gregory [33], under similar experimental conditions (tube inner diameter $11.6 \mathrm{~mm}$ and mercury vapour pressure range 2.7 to $13 \times 10^{-3}$ torr), found similar results 
and further showed that, at discharge currents equal to or larger than $1.5 \mathrm{~A}$, there could be density variations of about $50 \%$ in the cathode region. We note that, in general, the electron density values reported for surface wave produced plasmas as well as their density gradients make then comparable to the positive column of DC low current arc discharges rather than to that of glow discharges. However, if the wave frequency is decreased below $200 \mathrm{MHz}$ and the gas pressure is not too large, the plasma column should be more similar to the positive column of the DC glow discharge.

3.1.3 Electron temperature and electron-neutral collision frequency. - The measurement with a Langmuir probe of the electron temperature of a plasma produced by a travelling surface wave perturbs the wave field to such an extent that the result may be considered meaningless. However, when the plasma is sustained by a standing surface wave, a radially oriented Langmuir probe may be located at an axial position where the $E_{r}$ field is minimum, thus avoiding disturbances in the wave field [31]. This procedure also reduces the possible influence of the electric field on the probe current, but it assumes that the electron temperature does not depend on the local value of the electric field. Rogers and Asmussen [31], who proposed this method, observe that the temperature values are almost constant $(\simeq 2.5 \mathrm{eV})$ as a function of the product $(p a)$ over an interval $10^{-2}-2 \times 10^{-1}$ torr-cm ( $p$ is the gas pressure). They show that, for $(p a)$ values larger than 0.05 torr-cm, their measured temperature values lie above the temperature curve calculated as a function of $(p a)$ from the positive column theory $\left({ }^{5}\right)$.

Ferreira's theoretical model [22] yields an electron temperature curve as a function of $(p a)$ that behaves almost the same way as that obtained from the positive column theory (i.e., it decreases with $(p a)$ ), except it has everywhere slightly lower values. Ferreira's temperature curves are dependent on the electron density : the temperature decreases slightly with increasing density. The fact that Rogers and Asmussen experimentally observe a temperature that is approximately constant with $(p a)$, contrary to Ferreira's calculations, can probably be related to the fact that the electron energy distribution is not Maxwellian, as assumed in the theoretical model. In such a case, the calculated temperature values represent in some way, effective values that are required to maintain the plasma column against the losses of charged particles to the wall. Therefore, the predicted temperature values are more indicative of the form of the tail of the electron energy distribution than that of the body, making the comparison with probe measurements difficult to interpret.

The electron-neutral collision frequency value in a

$\left({ }^{5}\right)$ The positive column theory (Schottky's theory) assumes that the DC electric field is radially constant and that particles are lost by ambipolar diffusion to the walls, the electron temperature being also radially constant.

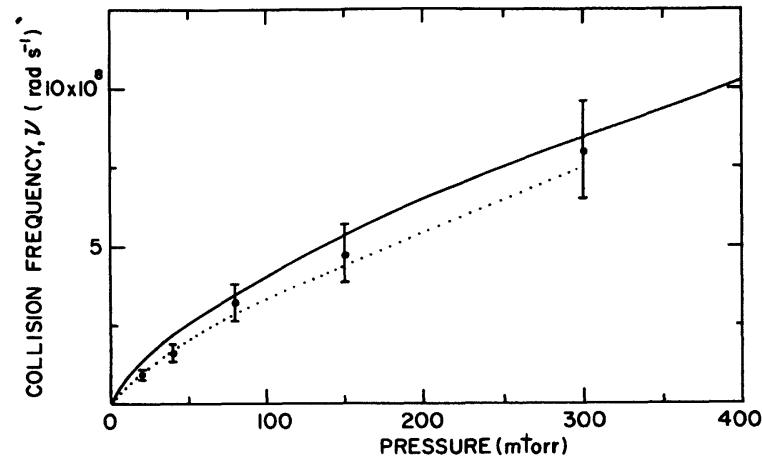

Fig. 21. - Collision frequency values $v$ as a function of pressure in a $26 \mathrm{~mm}$ diameter surface wave produced argon plasma. The wave frequency is $360 \mathrm{MHz}$. The experimental points are obtained from the fitting of the electron density axial distributions in figure 20 [29]. The solid line is calculated assuming Maxwellian electrons and ambipolar diffusion, using the Von Engel universal electron temperature curve. The dotted line is calculated from the electron temperature values determined by Ferreira [22].

surface wave produced plasma can be determined experimentally from the wave damping [7] or from the electron density axial distribution $[29,30]$. It can also be calculated from the published electron-neutral collision cross sections, provided the electron temperature is known. The points in figure 21 are collision frequency values determined from the experimental electron density axial distribution [29]. The full curve is that calculated using the electron temperature value estimated from the positive column theory [34]. The dotted line is calculated from the temperature values determined by Ferreira [22] which, as mentioned, are lower than those in positive columns. The agreement is definitely better at low pressures with Ferreira's model.

3.2 EXPERIMENTALLY OBSERVED PROPERTIES OF SURFACE WAVE PLASMA COLUMNS PRODUCED WITHIN A DIELECTRIC TUBE AT ATMOSPHERIC PRESSURES (SECOND TYPE PLASMA). - In this section, we consider surface wave plasmas sustained at atmospheric pressures that are completely contained within a dielectric tube. One end of the tube is connected to the gas supply, while the other opens into the room atmosphere. Typical gas flow rates in argon are 0.2 to $151 / \mathrm{min}$. (gas pressure $\simeq 1.5$ bar), the plasma tending to be unstable outside this range. The launcher is located close to the gas supply end of the tube and oriented so that the surface wave propagates toward the other end. The best dielectric material for such tubes is fused silica because the permittivity and the loss tangent of this material do not vary much when its temperature changes, providing stable and reproducible microwave conditions. The tube temperature remains well below the melting point, though the plasma gas temperature can be higher. In fact the plasma is not in contact with the tube walls, because it is self-constricted to a dia- 
meter that is always smaller than that of the tube and it is centred on the tube axis.

The reason why the data that we report about this second type plasma are obtained in a very narrow range of pressures, around $1.5 \mathrm{bar}$, is because the experimental arrangement, in this case, can be greatly simplified. In fact, such filamentary plasmas can be observed at pressures as low as 50 torr, depending on the tube diameter. When the latter is large, typically for internal diameters between 8 and $20 \mathrm{~mm}$, one will instead see two or more short (colder) argon plasma filaments, usually off the axis and in rotation. For even larger tube diameters, it may become impossible to produce any plasma at all, because the diameter of the eventual plasma filament (typically 1 to $2 \mathrm{~mm}$ ) is too small compared to the launcher aperture, i.e., the field coupling with the plasma is too low. The largest value of launching efficiency is reached for launcher aperture to plasma diameter ratios that approach unity [35].

3.2.1 Length and diameter of the plasma column.Figure 22 shows how the argon plasma length increases with the microwave power accepted by the launcher. A shorter column length would be obtained with a gas having a higher ionization potential. Typically with helium at $700 \mathrm{~W}$, the column length is about $40 \mathrm{~mm}$, i.e., more than ten times shorter than with argon.

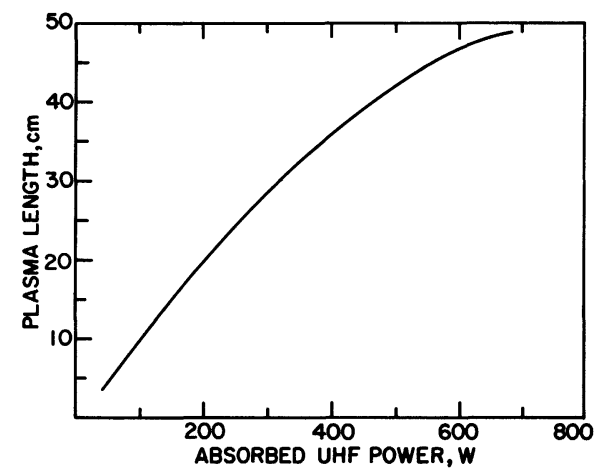

Fig. 22. - Length of the surface wave produced argon plasma within a dielectric tube at atmospheric pressures ( $\simeq 200 \mathrm{kPa}$ ), as a function of the microwave power absorbed by the combination launcher-plasma. The tube is fused silica with i.d. $4 \mathrm{~mm}$ and o.d. $6 \mathrm{~mm}$. The plasma is centred on the tube axis and is approximately $1 \mathrm{~mm}$ in diameter. The wave frequency is $915 \mathrm{MHz}$. (From [17].)

For tubes with internal diameters in the range 1 to $2 \mathrm{~mm}$, the plasma diameter decreases only slightly from the launcher exit to the end of the column : for example, in argon with a tube of internal diameter $1.94 \mathrm{~mm}$, it varies from 1.0 to $0.8 \mathrm{~mm}$ over a distance of about $400 \mathrm{~mm}$. The smaller the tube diameter, the less the plasma diameter varies axially : with a tube of internal diameter $0.92 \mathrm{~mm}$, the plasma diameter is about $0.6 \mathrm{~mm}$ over the total length obtained $(150 \mathrm{~mm})$ [24].

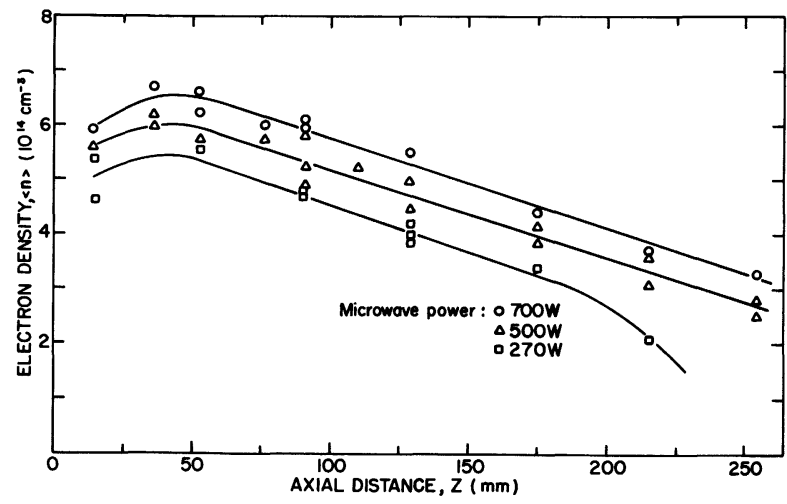

Fig. 23. - Measured cross-sectional average electron density $\langle n\rangle$ of the argon plasma filament produced within a dielectric tube at atmospheric pressures $(\simeq 200 \mathrm{kPa})$, as a function of the axial distance from the launcher exit, for three values of the microwave power to the launcher. The tube is fused silica with i.d. $1.94 \mathrm{~mm}$ and o.d. $8 \mathrm{~mm}$, and the plasma is about $1 \mathrm{~mm}$ in diameter. The surface wave frequency is $915 \mathrm{MHz}$. (From [24].)

3.2.2 Axial distribution of electron density. Figure 23 shows the cross-sectional average electron density measured in argon as a function of the axial position from the launcher exit, for three different values of the absorbed microwave power $\left({ }^{6}\right)$ (for 500 and $700 \mathrm{~W}$, the plasma column extends beyond the $250 \mathrm{~mm}$ plotted in figure 23). As it is the case with the reduced pressure plasma, the electron density value, past a certain distance from the launcher (see footnote 1), decreases linearly along the column. Likewise, the behaviour of the plasma column as the microwave power to the launcher is increased from $P_{1}$ to $P_{2}$ is exactly the same as with reduced pressure plasmas (compare figure 23 with figure 2) : the column length increases, the slope of the electron density is not modified, and the column obtained at power $P_{2}$ is made up of the plasma column observed at power $P_{1}$, plus an additional length of plasma added on the high electron density side of the former column. In other words, when the microwave power is increased to $P_{2}$, that part of the plasma column obtained at power $P_{1}$ appears to be simply pushed away from the launcher, without being affected by the power increase. In figure 23, when the power is set to $270 \mathrm{~W}$, one notes that the electron density decreases from about 5 to $2 \times 10^{14}$ electrons $/ \mathrm{cm}^{3}$ over a $200 \mathrm{~mm}$ length. With smaller diameter tubes, for comparable microwave powers, the density value close to the launcher is found to be larger, but the axial density gradient is larger and the plasma length smaller. For example, with a tube of $0.92 \mathrm{~mm}$ i.d., at $280 \mathrm{~W}$ in argon, the density decreases from

$\left.{ }^{6}{ }^{6}\right)$ The plasma electron density was determined from the Stark broadening of the $\mathrm{H}_{\beta}$ line $(486.1 \mathrm{~nm})$. To this end, the pure argon gas was replaced by an argon-hydrogen mixture containing $0.5 \%$ hydrogen [24]. 
$1.5 \times 10^{15}$ to $9 \times 10^{14}$ electrons $/ \mathrm{cm}^{3}$ over a plasma column length of less than $100 \mathrm{~mm}$ [24].

3.2.3 Temperatures. - The temperature and electron density values measured are not related by Saha's equation, i.e., the plasma is not in local thermodynamic equilibrium [36]. As a result, the plasma may be characterized by a gas temperature, an excitation temperature, and an electron temperature.

To determine the gas temperature (neutral atom temperature) of such argon or helium plasmas, we added a small amount of nitrogen, assuming that the temperature determined from the intensity distribution of the rotational levels of $\mathrm{N}_{2}$ is close to the main gas temperature. The recording of these rotational levels was performed in plasmas produced with $100 \mathrm{~W}$ or less. At a flow rate of $4.5 \mathrm{l} / \mathrm{min}$., the rotational temperature for the mixture $\mathrm{N}_{2}(0.3 \%)-\operatorname{Ar}(99.7 \%)$ ranges from $2150 \mathrm{~K}$ at $30 \mathrm{~W}$ to $2800 \mathrm{~K}$ at $90 \mathrm{~W}$ [36]. For helium, with the same percentage of nitrogen, at $100 \mathrm{~W}$, one finds $2700 \mathrm{~K}$ at a flow rate of $125 \mathrm{ml} / \mathrm{min}$., and $2000 \mathrm{~K}$ for a flow rate of $500 \mathrm{ml} / \mathrm{min}$. Thus, the gas temperature of argon and helium increases with the microwave power and decreases with the gas flow rate (especially with helium), a result that could be expected.

The excitation temperature obtained from the intensity distribution of ArI lines at $70 \mathrm{~W}$ decreases from $3700 \mathrm{~K}$ at $200 \mathrm{ml} / \mathrm{min}$. to $3300 \mathrm{~K}$ at $1.41 / \mathrm{min}$. [36]. In helium, in the power range $150-360 \mathrm{~W}$, the excitation temperature seems to be almost independent of the flow rate over the interval $50-300 \mathrm{ml} / \mathrm{min}$., yielding a value of about $4000 \mathrm{~K}$.

The electron temperature was not measured. Assuming the positive column theory to apply (ambipolar diffusion), the electron temperature is calculated to be of the order of $1 \mathrm{eV}$ in argon [24].

As a rule, the characteristics of these surface wave filamentary plasmas, as observed in argon, appear to be independent of the wave frequency [36]. This can probably be related to the fact that $v>\omega$. A systematic and complete study of such a plasma in helium is now in progress, in view of its application to elemental analyses (section 5.1.2).

3.3 THE SMALl Plasma-JET. - Let us consider what happens with the same experimental arrangement as in section 3.2 , when the dielectric tube extends only a few centimetres, say $5 \mathrm{~cm}$, outside the launching structure. As the power is raised above 30 to $40 \mathrm{~W}$, provided the gas flow is laminar, a filamentary argon plasma will enter the room atmosphere and continue over a few centimetres as a result of wave propagation (Fig. 24). The length of this plasma filament in free air, contrary to the case when it is enclosed within a dielectric tube, does not vary much with the microwave power and it is mainly determined by the time it takes for nitrogen to diffuse into the argon flow. The plasmajet tip is characterized by a yellow region that indicates that nitrogen is being excited. This excitation uses up

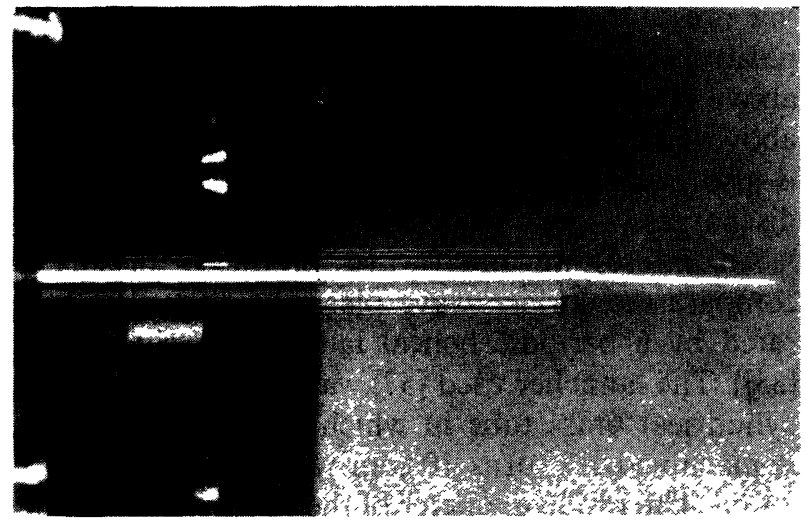

Fig. 24. - Photograph of a filamentary argon plasma extending partially outside the plasma tube into free air as a result of surface wave propagation. The launcher is on the left side of the picture. The argon flow is laminar at about $11 / \mathrm{min}$. and the tube i.d. is $6 \mathrm{~mm}$. (From [17].)

all the wave power. With $300 \mathrm{~W}$, the argon jet extends in the air about $40 \mathrm{~mm}$. With increasing microwave power, the heat capacity of this plasma-jet increases and, for example, tungsten wires of increasing diameters can be melted (with some help from the room oxygen).

4. Applications. - Surface wave produced plasmas can be used to replace with some advantages either DC discharge plasmas or other kinds of RF or microwave produced plasmas.

Section 3.1 indicated that the surface wave produced plasma column, in terms of electron temperature and electron density values, appears comparable to the positive column plasma of DC discharges in the (low current) arc regime. In comparison with DC discharges, one of the main advantages of microwave plasmas in general comes from the fact that there are no electrodes within the plasma. This eliminates electrode outgassing or pumping, electrode corrosion or wearout (especially with a filament or a coated cathode), and material deposit on the tube walls. All these effects result to some extent in the pollution of the plasma gas and, for sealed-off tubes, in limited lifetimes. These phenomena are particularly detrimental to the operation at low gas pressures of the positive column. The surface wave plasma, however, is exceptionally stable at low pressures and operates in a very straightforward way at ( $p a$ ) values as low as $0.2 \times 10^{-3}$ torr-cm $(500 \mathrm{MHz})$ in argon [37]. This $(p a)$ value corresponds to the minimum value that has been observed in positive columns [38]. An additional advantage of the surface wave plasma is that it is quiescent (low rate of electron density fluctuations $\left({ }^{7}\right)$ ) over all its operat-

$\left({ }^{7}\right)$ The rate of electron density fluctuations in surface wave plasma appears to be mainly determined by external conditions, such as the frequency and the power stability of the microwave power generator, the gas flow stability, the mechanical stability of the plasma tube, etc. 
ing pressure range, contrary to the situation in the positive column, which starts to be noisy at $(p a)$ values above 10 to $20 \times 10^{-3}$ torr-cm in mercury vapour and above 0.2 torr-cm in rare gases. A surface wave plasma is also free of the moving striations observed in DC discharges.

An interesting microwave produced plasma to compare the surface wave plasma with is that generated by a periodic helical launcher (Lisitano's coil [33]). The launcher used [37] was made from a hollow cylindrical brass tube in which a helical slotted line is machined : 7 turns $10 \mathrm{~mm}$ wide, width of the slot $2 \mathrm{~mm}$. The inside diameter of the brass tube is $30 \mathrm{~mm}$, to fit the plasma tube. This localized launcher generates a long plasma column, provided the column is submitted to an axial DC magnetic field, such that the electron-cyclotron frequency is larger than the wave frequency. A surface wave plasma, launched by a surfatron, was generated under similar conditions : the same tube diameter, the same gas pressure, and the same incident microwave power over the same frequency range were used. Also, the DC magnetic field required for the operation of the periodic launcher was applied to the surfatron plasma (this resulted in the propagation of a volume wave rather than a surface wave). Figure 25 shows that, under comparable conditions, the number of electrons produced per unit absorbed microwave power is larger with the surfatron plasma. It was also observed that with a surfatron, only the azimuthally symmetric mode is excited, while the helical launcher is found to operate alternately on at least two modes, the azimuthally symmetric mode and the dipolar mode, leading to a less stable and less reproducible plasma column. In addition, the fact

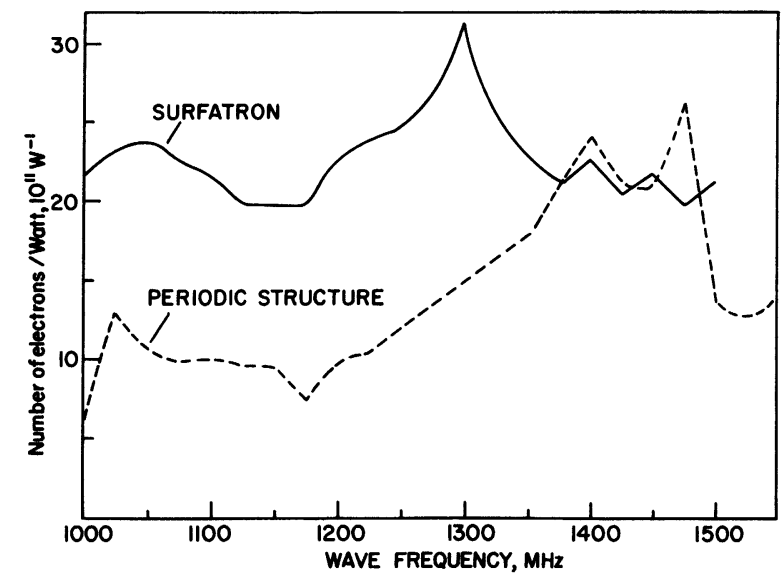

Fig. 25. - Comparison, as a function of the wave frequency, of the number of electrons produced by unit absorbed microwave power, by a surfatron launcher (azimuthally symmetrical surface wave) and a periodic helical structure. The plasma column is submitted to an axial DC magnetic field whose intensity is set so that the electron cyclotron frequency is 1.5 times the wave frequency. The gas is argon at 0.04 torr and the tube is pyrex (relative permittivity $\varepsilon_{\mathrm{g}}=4.52$ ) with inside and outside diameters, respectively, 25.4 and $29.8 \mathrm{~mm}$. (From [37].) that no axial DC magnetic field is required in producing surface wave plasma columns is a distinct practical advantage.

In section 4.1, we will see some specific applications where other RF and microwave produced plasmas are used and compared with surface wave plasmas. In general, it is observed that surface wave plasmas have a considerably lower electromagnetic radiation level than other microwave produced plasmas at the same frequency and power level.

4.1 Present applications. - 4.1.1 CW hydrogen fluoride (HF) laser. - In recent years, there has been a continuous effort in several laboratories towards the development of a versatile and small-size CW chemical HF or DF laser that could provide a sizeable $\mathrm{CW}$ power in the mid-infrared. The principle of these lasers is well known : fluorine atoms are mixed with hydrogen (or deuterium) molecules. The chemical reaction that follows produces a large number of $\mathrm{HF}$ (or DF) molecules in excited vibrational states. Thus, a population inversion is created and laser action will follow with proper optical cavity design [40].

The F-atoms can be produced in a DC, RF or microwave discharge in a mixture of F-bearing molecules, such as $\mathrm{SF}_{6}$, and a rare gas. For such purposes, $\mathrm{RF}$ or microwave produced plasma sources are preferable to DC discharges, in which the electrodes would be attacked by the fluorine atoms. Two types of microwave produced plasmas were tested by Bertrand et al. [41] and compared in terms of the laser output power, the electrical and chemical efficiencies, the operating conditions, and the quality of the laser beam. These are the large microwave plasma (LMP) [5], that uses a slow-wave structure which runs along the plasma tube, and the surface wave plasma.

The slow-wave structure is a linear, ladder-type, stripped-bar line, $18 \mathrm{~cm}$ long. It is operated at $2.45 \mathrm{GHz}$ and microwave power up to $2.5 \mathrm{~kW}$ could be used. As for the surface wave plasma, it is obtained from a water cooled surfatron, $8 \mathrm{~cm}$ long, operated at $915 \mathrm{MHz}$, with a maximum available power of $800 \mathrm{~W}$. In both cases, the plasma is produced in a mixture containing $\mathrm{SF}_{6}$, helium and oxygen, the relative concentration of these gases being set so as to maximize the laser output power [41]. The total pressure is about 5 torr. The laser operates in the 2.6 to $3 \mu \mathrm{m}$ wavelength region, and its multiline output power, for example at $800 \mathrm{~W}$ of microwave power, can attain $9 \mathrm{~W}$, provided sufficiently fast flow rates are realized (this is necessary to remove HF molecules once they returned to the ground state, in order to avoid photon absorption). Typical single-mode single-line laser powers for microwave powers in the range $400-500 \mathrm{~W}$ are 3 to $10 \mathrm{~mW}$ CW.

It was found [41] that, when operated at the same microwave power level, both devices have a comparable laser output power. However, the slow-wave structure can sustain higher microwave power, pro- 
viding larger laser output power. This is due to the fact that this surfatron uses a coaxial cable as a coupling means and that such cables are heated by dielectric losses, which limit their microwave power capacity. In the present case, the surfatron could be operated safely for long term periods at powers up to $500 \mathrm{~W}$. Nevertheless, the construction of a compact chemical laser gives the surfatron an advantage over the LMP slow-wave structure which is physically larger and which also requires the use of a Faraday cage to protect against electromagnetic radiations. When operated under the appropriate conditions, the surface wave plasma does not radiate significantly, the surface wave field being almost completely damped in the transverse direction, over a few wavelengths, so that no Faraday cage is needed.

This work was performed at the Ecole Polytechnique de Montréal (affiliated with the Universite de Montréal) under the direction of Professors L. Bertrand and J. M. Gagné.

4.1.2 Elemental analyses by optical emission spectroscopy. - Atomic emission spectroscopy is a powerful technique for qualitative and quantitative elemental analyses. Several atomization and excitation sources were developed for that purpose but it is only recently that different kinds of plasmas were used as excitation sources.

Two types of plasma are commercially available, namely the direct current argon plasma (DCP) [42] and the radiofrequency inductively coupled argon plasma (ICP) [43]. In general, the analytical performances of the ICP source are superior to those of the DCP in terms of detection limits, dynamic range of element concentrations, and freedom from chemical interferences. However, the DCP can better tolerate high salt containing samples than the ICP, and it is also less expensive to operate : it requires a flow rate of only 2 to $3 \mathrm{l} / \mathrm{min}$. of argon, whereas the ICP requires more than $15 \mathrm{l} / \mathrm{min}$. The DCP generator is also less expensive than the RF generator needed for the ICP. Both commercial plasma sources cannot routinely be operated in gases other than argon or argon based gas mixtures. A third type of plasma, the microwaveinduced plasma (MIP) has also been used as excitation source for elemental analyses. The most commonly used MIP sources are operated in argon or helium (helium is more efficient than argon in terms of excitation) at low microwave power $(<200 \mathrm{~W})$ in a fused silica tube at a frequency of $2.45 \mathrm{GHz}$. These devices requires a very low gas consumption compared to DCP or ICP plasmas. The major problems encountered with the MIP sources are their long term stability related to the change in coupling between the microwave generator and the plasma with time. Two new MIP devices, the Beenakker $\mathrm{TM}_{010}$ cavity [44] and the surfatron [36] were recently adapted and used to sustain argon or helium plasmas at atmospheric pressures. Comparisons were made between these two plasma sources. These show that the surface wave plasma provides a better power coupling between the plasma and the generator (zero reflected power under a large variety of operating conditions), and is more stable over a long period of time. This good stability is partly due to the fact that only one mode of propagation or operation is observed with the surfatron plasma [36]. It is also more quickly and easily tuned : no tuning stubs are needed as is the case with all other MIP sources.

The MIP sources were most commonly used as excitation sources for an atomic emission gas chromatography detector. A low power $(<200 \mathrm{~W})$ atmospheric pressure helium plasma sustained by a surfatron at $2.45 \mathrm{GHz}$ in a $3 \mathrm{~mm}$ i.d. fused silica tube has been adapted to the outlet of a gas chromatograph. A fused silica capillary chromatographic column $(0.25 \mathrm{~mm}$ i.d.) is used for separation. Its outlet is located at 2 to $5 \mathrm{~mm}$ behind the helium plasma surfatron, and all the effluents are injected in the plasma. The line intensities emitted by carbon atoms, chlorine, bromine and iodine single charged ions were measured with a spectrophotometer. The analytical results obtained are summarized in table $I[45,46]$. These values are equivalent or better than previously reported values obtained with other MIP devices [47, 48]. The microwave power was set to $90 \mathrm{~W}$ and the helium flow rate was $25 \mathrm{ml} / \mathrm{min}$.

More recently, we have studied the variations in emitted line intensities for non-metals as a function of microwave power for several analytes in the surfatron helium plasma. The power was increased from our previous $100 \mathrm{~W}$ to $360 \mathrm{~W}(915 \mathrm{MHz})$ and we noted that the signal-to-noise ratio of the emitted light increased by a factor of about 25 . This means that the use of high microwave power $(\simeq 350 \mathrm{~W})$ helium plasmas should allow us to still improve the analytical performances.

The effects of other operating parameters like the gas flow rate, the plasma tube diameter, configuration and position, on emitted line intensities were also systematically investigated. The optimum gas flow rate is found to be at less than $100 \mathrm{ml} / \mathrm{min}$. The emitted

Table I. - Analytical performances for the chromatographic detector.

$\begin{array}{cccc}\text { Element } & \begin{array}{c}\text { Wavelength } \\ (\mathrm{nm})\end{array} & \begin{array}{c}\text { Detection } \\ \text { limit }\left(^{*}\right) \\ (\mathrm{pg} / \mathrm{s})\end{array} & \begin{array}{c}\text { Dynamic } \\ \text { range }\left(^{* *}\right)\end{array} \\ \overline{\mathrm{C}} & - & - & - \\ \mathrm{Cl} & 247.9 & 2-5 & 10^{3} \\ \mathrm{Br} & 479.5 & 2-4 & 10^{3} \\ \mathrm{I} & 470.5 & 7-12 & 10^{3} \\ & 206.9 & 0.2-2 & 10^{3}\end{array}$

(*) The detection limit is defined as the analyte weight per unit time which produces a signal equal to twice the standard deviation of the background intensity.

$\left.{ }^{* *}\right)$ The dynamic range is defined as the concentration range for which the signal is proportional to the concentration of the analyte. 
intensity increases when the plasma tube diameter is decreased. A threefold increase in intensity is obtained by decreasing the inner diameter from 3 to $1.5 \mathrm{~mm}$.

The helium surfatron plasma was also tested $\left({ }^{8}\right)$ as an excitation source for liquid sample analysis [49]. The plasma was operated at atmospheric pressures ( $\simeq 1.5 \mathrm{bar}$ ) with a gas flow rate of less than $500 \mathrm{ml} / \mathrm{min}$. and a microwave power of $130 \mathrm{~W}$. The detection limits obtained with a non optimized system are one or two orders of magnitude higher than for ICP plasmas. Some chemical interferences were also noted. Nevertheless, considering the low cost of this MIP system and the further possible developments that can be achieved, these plasmas will most certainly play an important role in elemental analyses by atomic emission spectroscopy.

This work is performed at the Département de Chimie, Université de Montréal, under Professor J. Hubert.

4.1.3 Ion source. - The aim pursued with this application was the design of a pulsed-monoenergetic ion source (hydrogen or helium) suitable for space experiments [50]. The requirements are for a maximum ion current of about $30 \mathrm{~mA}$, at approximately $10 \mathrm{keV}$ with an energy spread of less than $100 \mathrm{eV}$. The angular dispersion of the beam must be less than $15^{\circ}$. The total electrical power consumption should be limited to $500 \mathrm{~W}$ and the total weight, including the ion gun, the gas handling system and the electronics, but excluding the high voltage supply, must not exceed $2.5 \mathrm{~kg}$. The usual spatial constraints should also be met, such as, for example, good reliability, compatibi-

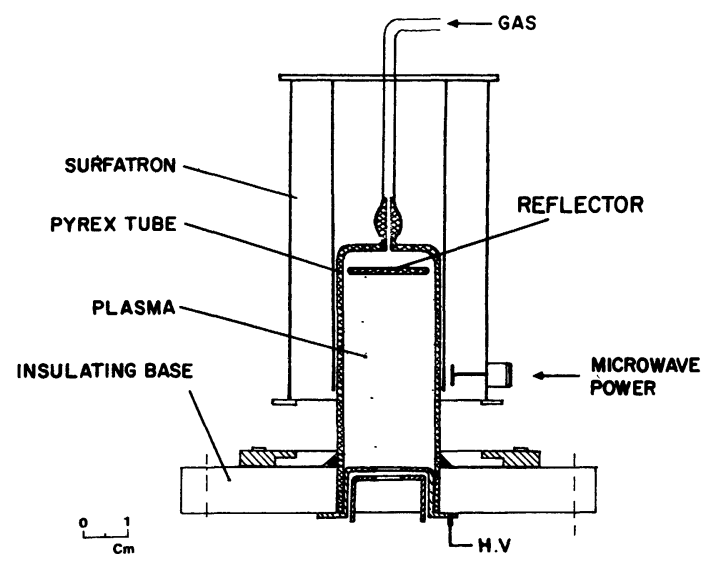

Fig. 26. - Schematic diagram of an ion source based on a surface wave produced plasma. The launcher is a surfatron operated at $870 \mathrm{MHz}$ with a microwave power of about $65 \mathrm{~W}$. The pyrex tube i.d. is about $20 \mathrm{~mm}$. The reflector prevents the wave from ionizing further up the gas inlet and also serves to obtain a non turbulent gas flow in the plasma. (From [51].)

$\left({ }^{8}\right)$ This work was performed under the France-Québec Scientific Agreements (01-02-07) in collaboration with Dr. J. M. Mermet, Service Central d'Analyse du C.N.R.S., Vernaison, France.

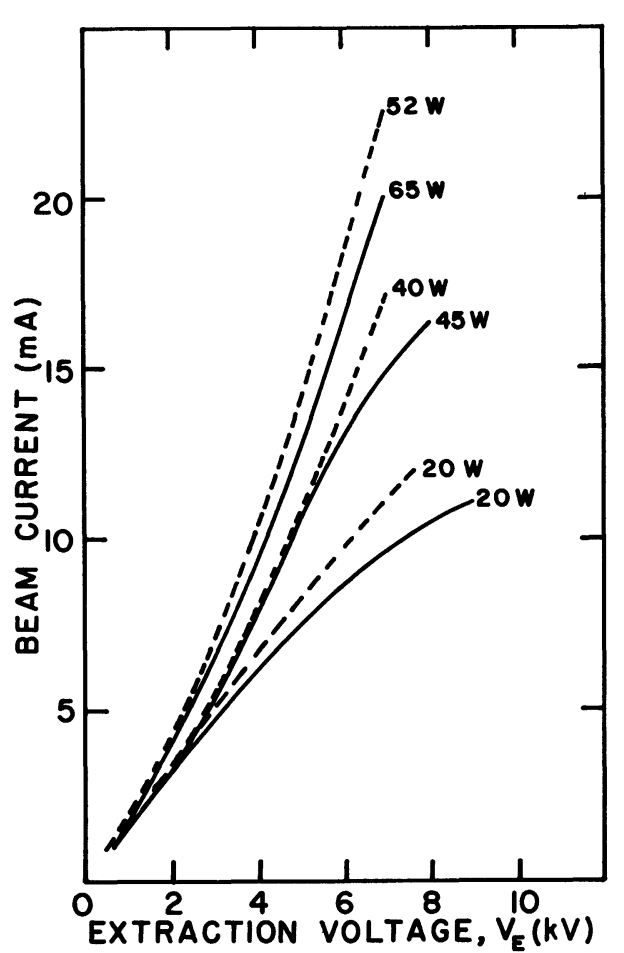

Fig. 27. - Proton beam current yielded by a surface wave based ion source, as a function of the extraction voltage $V_{\mathrm{E}}$, for various values of the microwave power absorbed by the plasma source. The full lines are from an ion source with a one hole extractor, while the dashed lines correspond to an extractor with seven holes. The hydrogen gas pressure in the plasma source is 0.055 torr for the one hole device and 0.08 torr for the seven hole variant. The surface wave frequency is $870 \mathrm{MHz}$. The observed ion current dependence on the extraction voltage is within the range $V_{\mathrm{E}}^{1.25}$ and $V_{\mathrm{E}}^{1.4}$. (From [51].)

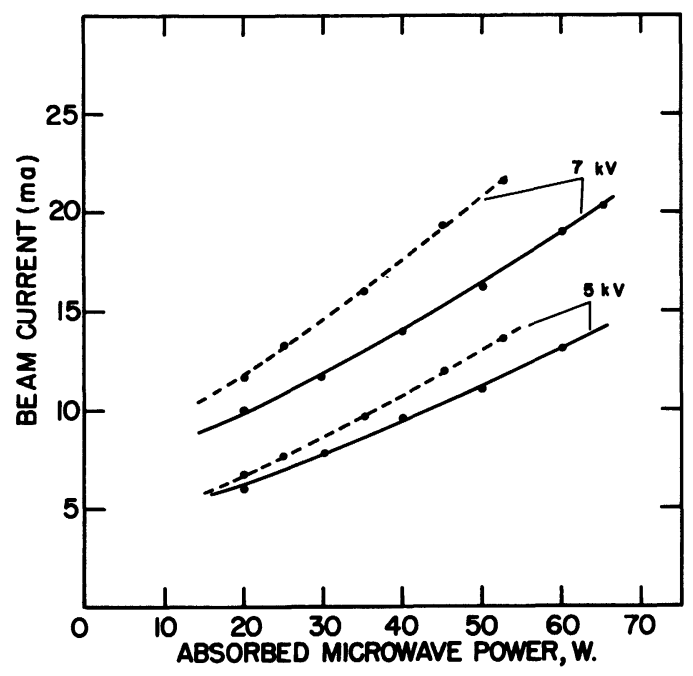

Fig. 28. - Proton beam current yielded by a surface wave based ion source, as a function of the microwave power absorbed by the plasma source. The full lines are from an ion source with a one hole extractor (Fig. 26), while the dashed lines correspond to an extractor with seven holes. Two extraction voltage values are represented, 5 and $7 \mathrm{kV}$. The hydrogen gas pressure in the plasma source is 0.055 torr for the one hole device and 0.08 torr for the seven hole variant. The surface wave frequency is $870 \mathrm{MHz}$. (From [51].) 
Table II. - Comparison between two ion sources adapted for space experiments.

\begin{tabular}{|c|c|c|}
\hline Parameters & Duoplasmatron & source (surfatron) \\
\hline Beam current (Hydrogen) & $10 \mathrm{~mA}$ & $20 \mathrm{~mA}$ \\
\hline Extraction voltage & $10 \mathrm{kV}$ & $7 \mathrm{kV}$ \\
\hline Electrical supply & $\begin{array}{l}\text { - Hot cathode }: 100 \mathrm{~W} \\
\text { - Discharge }: 200 \mathrm{~W}\end{array}$ & 50-65 W Microwave power \\
\hline Magnetic field & Permanent magnets & none \\
\hline Gas consumption & $\simeq 100 \mathrm{ml} / \mathrm{h}$ & $\simeq 500-650 \mathrm{ml} / \mathrm{h}$ \\
\hline Weight (gun only) & $2.5 \mathrm{~kg}$ & $450 \mathrm{~g}$ \\
\hline Cooling & Required & Not necessary \\
\hline Particular requirements & $\begin{array}{l}\text { - filament must be kept under vacuum } \\
\text { at all time } \\
\text { - filament and hv supply must be insu- } \\
\text { lated one from the other }\end{array}$ & \\
\hline
\end{tabular}

Surface wave produced ion source (surfatron)

$20 \mathrm{~mA}$

$7 \mathrm{kV}$

none

$\simeq 500-650 \mathrm{ml} / \mathrm{h}$

$450 \mathrm{~g}$

$2.5 \mathrm{~kg}$

filament must be kept under vacuum

lated one from the other lity with the rest of the spacecraft equipment (including a low electromagnetic radiation level), and the ability to withstand vibrations and thermal gradients. Three different ion sources intended for space experiments were tested by Dr. D. Henry and collaborators (Dr. Y. Hajlaoui, Dr. Y. Arnal) [51] at the CRPE/CNET research centre, 45045 Orléans, France. We report on the one built around a surfatron launcher.

The surfatron produces a plasma within a $20 \mathrm{~mm}$ i.d. pyrex tube and ions are removed using a Ward type or diaphragm extractor. Figure 26 shows such a source with a one hole extractor. A seven hole variant was also tested. The surfatron is operated at $870 \mathrm{MHz}$ with a maximum available microwave power of $65 \mathrm{~W}$. The launcher itself is about $75 \mathrm{~mm}$ long and $45 \mathrm{~mm}$ in diameter. It is made from aluminium and it weights less than $150 \mathrm{~g}$. Figure 27 presents the ion current obtained in hydrogen as a function of the extraction voltage, for various values of the microwave power absorbed by the launcher. The gas pressure in the pyrex tube is 55 mtorr for the one hole extractor and $80 \mathrm{mtorr}$ for the seven hole variant. Theoretically, the ion current should depend on the extraction voltage $V_{\mathrm{E}}$ as $V_{\mathrm{E}}^{3 / 2}$. Experimentally, it is found to depend on $V_{\mathrm{E}}$ within the range $V_{\mathrm{E}}^{1.25}-V_{\mathrm{E}}^{1.4}$. Figure 28 shows the ion current obtained in hydrogen as a function of the microwave power absorbed by the launcher, for two given extraction voltages. It indicates that a proton current of about $20 \mathrm{~mA}$ is attained at $7 \mathrm{kV}$ with a microwave power in the range $50-65 \mathrm{~W}$. With argon and a plasma gas pressure of $85 \mathrm{mtorr}$, under similar conditions, the ion current is about $4 \mathrm{~mA}$ with $65 \mathrm{~W}$ (the ion current depends on the ion mass as $M^{-1 / 2}$ ). The energy dispersion observed at full halfwidth is of the order of $50 \mathrm{eV}$. The angular divergence is about $10^{\circ}$ FWHM.

Some parameters of this source are compared in table II with a duoplasmatron source, that is considered by many authors as a reference ion source. In the present case, the duoplasmatron is a space-designed model custom-made by SPIRE Corp. (USA). The performance of the surfatron ion source appears quite satisfactory, except for the gas consumption : $650 \mathrm{ml} / \mathrm{h}$ for the one hole extractor and $950 \mathrm{ml} / \mathrm{h}$ for the seven hole one, i.e., respectively about 5 and 10 times that of the duoplasmatron. Though such a gas consumption is not a handicap for the intended space applications, it might prevent the use of the source for other applications. Our knowledge of surface wave produced plasmas makes us inclined to think that this problem might be overcome by applying a larger microwave power level to the surfatron, by increasing the wave frequency, and reducing the plasma tube diameter. Preliminary results in that direction, at $2450 \mathrm{MHz}$ but with only $10 \mathrm{~W}$ available, in a tube with inner diameter $4 \mathrm{~mm}$, yield an ion current that is about five times higher than the corresponding values at $10 \mathrm{~W}$ in figure 27. Work is still in progress.

4.1.4 Thin oxide film creation. - A series of experiments with microwave plasmas aimed at developing a new technology for the low temperature $\left(T \lesssim 600^{\circ} \mathrm{C}\right)$ creation of high quality oxide films has been undertaken in many countries. Such a technology is of great importance for forming isolation and for final passivation layers on different semiconductor devices such as solar cells, integrated optical devices and microwave devices.

The present application concerns one such possible method of film creation, the reactive plasma deposition technique [52]. It uses the fact that gaseous chemical reactions can be efficiently produced when some of the reactants are activated by a plasma rather than thermally. The advantage of this technique is that the entire process of film formation, including the production of highly reactive species that would require intolerably high temperatures to be achieved thermally, can be carried out at temperatures of $350^{\circ} \mathrm{C}$ or less with a plasma : in general, the lower the temperature, the higher the quality of the deposit obtained. The 
absence of electrodes in RF or microwave plasmas is a definite advantage over DC discharges when trying to maintain impurities to a very low level. The interest of the surface wave discharge is that it does not require an external magnetic field and it can operate in a very broad pressure range (in small tubes), from about $10^{-5}$ torr to atmospheric pressures.

In the present case, the surface wave plasma provides active nitrogen which is then mixed with $\mathrm{SiH}_{4}$, yielding deposits of silicon nitride $\left(\mathrm{Si}_{3} \mathrm{~N}_{4}\right)$ on substrates located in or near the reaction zone (Fig. 29). Due to the flexibility of the surface wave plasma, the growth rate of films can be carefully controlled by regulation of the reactant flow rates, by the partial pressures of $\mathrm{N}_{2}$ and $\mathrm{SiH}_{4}$, by the magnitude of the microwave power and by the substrate temperature. With such a flexibility, it is expected that a careful design of the deposition reactor makes it possible to create films on several samples simultaneously. Moreover, it should be possible to create films not dependent on the substrate chemical composition, i.e., in particular, multilayer surface structures [52].

This work is performed at the Institute of Plasma Physics in Prague and at the Czech Technical University by Dr. Musil et al.

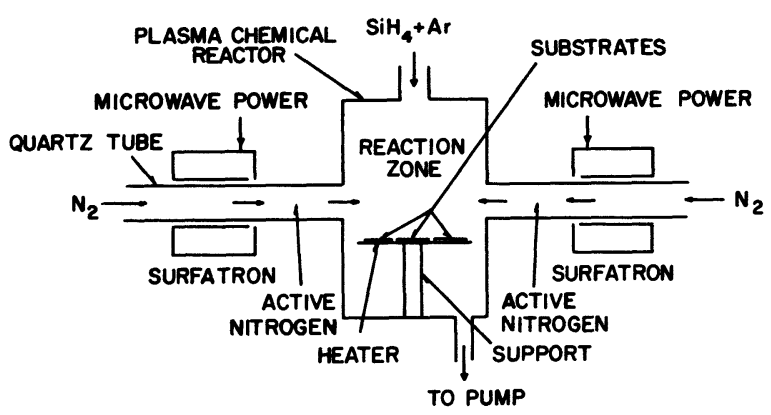

Fig. 29. - Schematic diagram of the $\mathrm{Si}_{3} \mathrm{~N}_{4}$ deposition system with surface wave produced plasmas. The gas pressure can be varied from $10^{-5}$ torr to atmospheric pressure. (From [52].)

4.1.5 A general purpose low microwave power plasma source at atmospheric pressures. - An interesting small plasma source was designed that permits the production at atmospheric pressures of almost any excited species with relatively low microwave power [17]. A concentric double wall fused silica tube is used (Fig. 30). A surface wave argon plasma is first produced in the central tube using a surfatron launcher. Then the gas to be excited is introduced in the outer tube through a lateral inlet and it mixes with the plasma in the nozzle. This is an easy way to obtain relatively large percentages of ions and excited states of given atoms and molecules. To completely sustain a plasma made from gases that have much higher ionization potentials or larger loss rates than argon, for example $\mathrm{N}_{2}$, would require much more microwave power than with the present method. A mixture containing up to

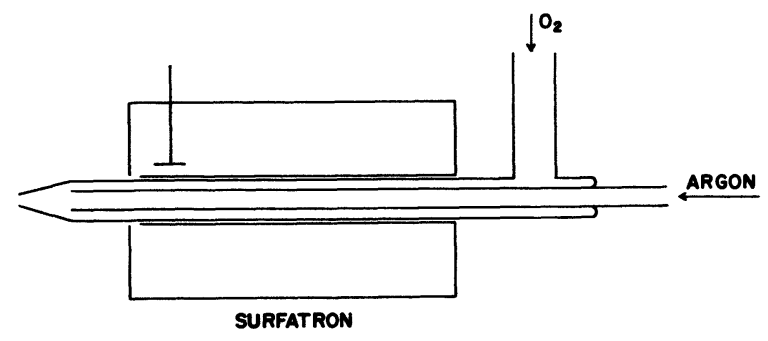

Fig. 30. - Simplified diagram of a general purpose low microwave power plasma source at atmospheric pressures. A surface wave produced argon plasma is generated in the central tube. Then gases (with higher ionization potentials or larger loss rates than argon) are introduced in the outer tube by the lateral inlet. They mix in the nozzle with the excited argon species. This enables one to obtain flames of various compositions. (From [17].)

$50 \%$ of excited $\mathrm{O}_{2}$ or $\mathrm{N}_{2}$ in argon can be obtained from an argon plasma sustained with less than $200 \mathrm{~W}$.

4.1.6 Spectral lamps. - The fact that very stable and reproducible plasmas can be achieved with surface waves, that there are no electrodes in contact with the plasma, and that large densities of excited atoms can be obtained, are indications that this plasma may be used to provide interesting spectral lamps. Furthermore, the fact that the radial profile of the population density of radiative levels has a maximum close to the tube wall (Section 3.1.1) enables large emission intensities to be recorded outside the plasma, even when photon trapping is important. This seems to be a distinct advantage of microwave produced plasmas over DC positive column plasmas, where the emitted intensity is maximum on the axis but might be significantly reduced in crossing the plasma [53].

One such spectral lamp designed for UV emission has been qualitatively tested [17]. It uses a surface wave argon plasma produced inside a vacuum vessel. Part of the wave propagation occurs over a dielectric free region, i.e., the plasma is the only propagating medium (Fig. 31). Two surfatrons aimed at each other are used for this purpose. With a proper setting of the gas flow

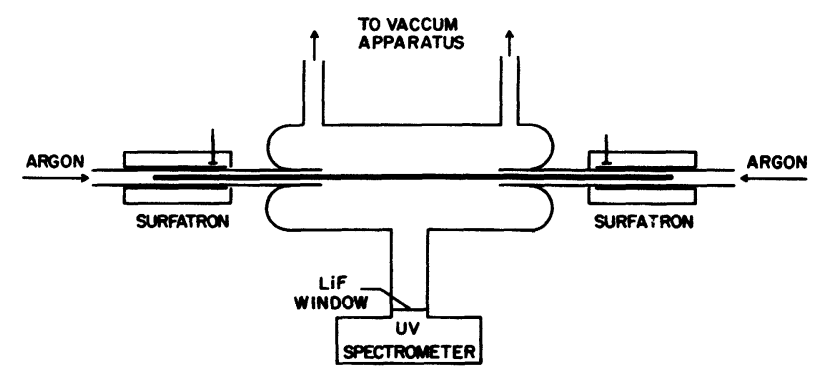

Fig. 31. - Schematic diagram of an intense, luminous and very stable UV spectral lamp. Two surface waves merge to form a dielectric-free plasma at the centre of the lamp. The argon gas pressure could be varied from about 200 torr up to the atmospheric pressure. The UV light leaves the lamp through a large LiF window. (From [17].) 
in each surfatron tube, a very stable confined plasma is obtained in the dielectric-free region, over a pressure range extending from about 200 torr to the atmospheric pressure. With this arrangement, lithium fluoride and magnesium fluoride windows are not in contact with the plasma. The emission lines detected are strong.

Another lamp, designed for optical absorption measurements in the visible range of wavelengths, was tested (Fig. 32). It is made of a $1.5 \mathrm{~mm}$ i.d. pyrex tube, about $150 \mathrm{~mm}$ long, connected to a large gas reservoir. The tube has been outgassed at $10^{-7}$ torr and then filled with pure argon at 0.4 torr. The plasma is produced with a surfatron operated at $900 \mathrm{MHz}$ and the microwave power, about $65 \mathrm{~W}$, can be modulated at $1 \mathrm{kHz}$ to allow for lock-in detection. The line intensities were found to be much more stable as a function of time than those obtained with some commercially available spectral lamps using DC discharges at pressures of the order of one torr : in particular, there is no noticeable drift in line intensities, at least for the first 100 hours or so of operation over a one year period. These lamps are easy to make. Two viewing directions can be used to look at the light from the plasma tube as shown in figure 32 . The axial viewing direction (1) yields a line profile for ArI $696.5 \mathrm{~nm}$ that is slightly self-absorbed with a true half-width, $\Delta \sigma_{1}=60 \times 10^{-3} \mathrm{~cm}^{-1}$. The perpendicular viewing direction (2) gives a gaussian (Doppler) profile halfwidth of $\Delta \sigma_{2}=36 \times 10^{-3} \mathrm{~cm}^{-1}$, corresponding to a discharge temperature of $500 \mathrm{~K}$.

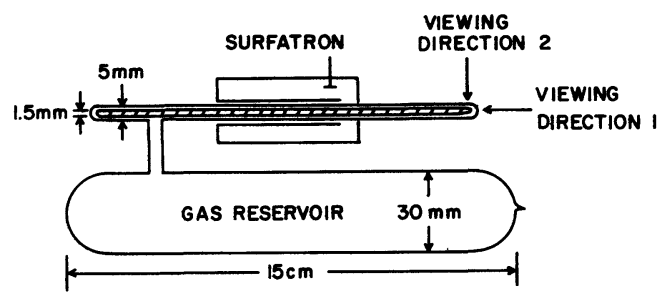

Fig. 32. - Simple spectral lamp designed for optical absorption measurements. The tube is filled with the proper gas at pressures ranging from 0.4 to a few torr. The surface wave is launched with a surfatron at $900 \mathrm{MHz}$, with about $65 \mathrm{~W}$ of microwave power. Multiple wave reflections can be achieved. Viewing direction 1 presents self-absorbed lines, while viewing direction 2 yields pure Doppler line profiles. (From [28].)

4.1.7 Discharge tube outgassing. - The fact that the surface wave electric field is maximum at the tube wall for reduced pressure plasmas leads, at high enough wave power, to a large heating of the tube internal wall, especially when operating at high electron densities (large wave frequencies or multiple wave reflection conditions). This effect can be used to efficiently outgas discharge tubes, before they are sealed-off with a pure gas.

Such an outgassing method was used to prepare cold cathode DC discharge tubes that are sealed-off with a pure gas and used for optical absorption measurements. These tubes are U-shaped, i.e., the electrodes are perpendicular to the positive column axis. A surfatron launcher, that can be dismounted into two halves in a plane parallel to the axis, is easily positioned at various places along the tube, including the electrode area. The tube is filled with the corresponding gas and a surface wave plasma is produced at $1000 \mathrm{MHz}$ (the available microwave power was about $65 \mathrm{~W}$ ). The gas pressure is then progressively decreased by pumping with a vacuum system to pressures of the order of $10^{-3}-10^{-4}$ torr. The outgassing is so efficient that, at the beginning of the process, a plasma can be sustained at pressures around $10^{-4}$ torr, with continuous pumping, i.e., the outgassing of the walls provides the necessary gas to maintain the plasma. Repeating this treatment for a few hours seems to be equivalent to at least 24 hours of baking at $300^{\circ} \mathrm{C}$.

\subsection{FURTHER POTENTIAL APPLICATIONS. -} 4.2.1 Laser medium. - The fact that the radial distributions of excited atoms in surface wave plasmas can be varied and almost shaped as desired, appears as an interesting possibility for laser media. Preliminary experiments (Bertrand and Moisan) were carried out to achieve a surface wave operated helium-neon laser in capillary tubes. No lasing action could be observed. By comparing with a DC discharge heliumneon laser, it was clear that the electron density in the surface wave plasma $(915 \mathrm{MHz})$ was much too large and, possibly, that even ion states were excited (in that respect, the design of surface wave ion lasers would appear promising). Considering the properties reported for the first type of surface wave produced plasma, one way of lowering the electron density is to reduce the wave frequency and to increase the plasma tube inner diameter.

4.2.2 Plasma chemistry. - Once again the flexibility in the radial profiles of excited atoms, in particular a possible large cross-sectional average density of a given excited species, and the possibility of producing long plasma columns are interesting for plasma chemistry. For a review on reduced-pressure microwave plasma for chemistry, see reference [54].

4.2.3 Plasma etching. - It is well known that the electronic industry is considering plasma etching (dry etching) as a powerful technique for the fabrication of integrated circuits. Compared with wet etching, plasma etching offers better line fidelity and higher resolution, greater dimension tolerance, and process simplification. Various types of plasmas are now being tested in that respect, in view of defining the best possible industrial plasma etching process. The fact that it is possible to control the spatial distribution of excited atoms and ions with surface wave produced plasmas gives these an interesting advantage over DC and RF plasmas. The absence of electrodes, the perfect reproducibility of surface wave produced plasmas, and the 
possibility of biasing the wafer by an independently controlled voltage source should also be mentioned for such an application.

5. Conclusion. - The properties of azimuthally symmetrical surface wave produced plasmas have been reviewed. Some demonstrated applications have been presented that indicate a great potential for surface wave produced plasmas. However, given the fact that the control of the plasma parameters and the physical dimensions of surface wave produced plasmas are very different from those of the other types of plasmas presently used in the applications described, the use of surface wave plasmas will require new approaches. Nevertheless, as indicated, several distinct advantages associated with surface wave produced plasmas have been identified for a number of applications which merit further developments.

An interesting result brought about by the present study concerns the problem of microwave produced plasmas in general. The fact that the properties of the wave producing the surface wave plasmas are already well known, that experimentally only one azimuthal mode of propagation is present, provides remarkable possibilities of achieving clear and neat comparisons between experiments and theory. In that respect, the theoretical models developed and verified for this type of plasma can certainly be extended and generalized to understand more clearly other microwave produced plasmas.

Acknowledgments. - The authors wish to thank Prof. H. W. Van Andel for commenting the manuscript. We are also indebted to Mr. F. Roy, R. Lemay and R. Martel (Université de Montréal) for their technical assistance. This project was made possible through the France-Québec scientific agreements (Projets intégrés 01-02-19, 01-02-07) and, in part, through a NATO grant (RG. 142-81).

\section{References}

[1] Messiaen, A. M., Vandenplas, P. E., Appl. Phys. Lett. 15 (1969) 30.

[2] Halverson, S. L., Hatch, A. J., Appl. Phys. 14 (1969) 79.

[3] Bloyet, E., LePrince, Ph., Milleon, H., J. Physique 34 (1973) $185-195$

[4] Moisan, M., Plasma Phys. 16 (1974) 1.

[5] Bosisio, R. G., Weissfloch, C. F., Wertheimer, M. R., J. Microw. Power 7 (1972) 325-346.

[6] Dovzhenko, V. A., Mel'nichenko P. O., Solntsev, G. S., Sov. Phys. Tech. Phys. 22 (1977) 190.

[7] Zakrzewski, Z., Moisan, M., Glaude, V. M. M., Beaudry, C., LePrince, P., Plasma Phys. 19 (1977) 77-83.

[8] Barlow, H. M., Brown, J., Radio Surface Waves (Oxford : Clarendon Press) 1962.

[9] Trivelpiece, A. W., Slow Wave Propagation in Plasma Waveguides (California Inst. Techn. Report 7) May 1958 (Ph. D. Thesis) June 1958.

[10] Moisan, M., Shivarova, A., Trivelpiece, A. W., Plasma Phys. 24 (1982) 1331-1402.

[11] Shivarova, A., Zhelyazkov, I., Plasma Phys. 20 (1978) 1049-1073.

[12] Moisan, M., Leprince, P., Beaudry, C., Bloyet, E., Perfectionnements apportés aux dispositifs d'excitation, par des ondes HF, d'une colonne de gaz enfermée dans une enveloppe, Brevet (Patent) France 74.36378, 1974.

[13] Moisan, M., Beaudry, C., Leprince, P., IEEE Trans. Plasma Sci. PS-3 (1975) 55-59.

[14] Bloyet, E., Leprince, P., Marec, J., Moisan, M., Revue Phys. Appl. 12 (1977) 1719. Also,

Bloyet, E., Leprince, P., Llamas Blasco, M., Marec, J., Phys. Lett. 83A (1981) 391.

[15] Moisan, M., Zakrzewski, Z., Pantel, R., J. Phys. D 12 (1979) 219-237.

[16] ZuCKer, F. J., Antenna Engineering Handbook (New York : McGraw-Hill, Jasik; H., editor) 1961, chap. 4 (Surface and leaky-wave antennas).
[17] Moisan, M., Pantel, R., Hubert, J., Bloyet, E., Leprince, P., Marec, J., Ricard, A., J. Microw. Power 14 (1979) 57.

[18] Goubau, G., Proc. IRE 39 (1951) 619.

[19] Tuma, D. R., Rev. Sci. Instrum. 41 (1970) 1519-20; also :

KAMPMANN, B., Z. Naturforsch. 34a (1979) 414 and 423.

[20] Trivelpiece, A. W., Slow-Wave Propagation in Plasma Waveguides (San Francisco Press) 1967.

[21] Moisan, M., Pantel, R., Ricard, A., Glaude, V. M. M., LePrince, P., Allis, W. P., Distribution radiale de la densité électronique et de la densité des atomes excités dans une colonne de plasma produite par une onde de surface (Université de Montréal, Phys. Dept. : Internal Report) 1979.

[22] Ferreira, C. M., J. Phys: D 14 (1981) 1811-30.

[23] Moisan, M., Pantel, R., Ricard, A., Glaude, V. M. M., Leprince, P., Allis, W. P., Revue Phys. Appl. 15 (1980) 1383-97.

[24] Moisan, M., Pantel, R., Hubert, J., Propagation of a surface wave sustaining a plasma column at atmospheric pressure (Université de Montréal, Phys. Dept : Internal Report) 1980.

[25] Moisan, M. Pantel, R., Ricard, A., Can. J. Phys. 60 (1982) 379-82.

[26] Kato, I., Tsuchida, H., Nagai, M., J. Appl. Phys. 51 (1980) 5312.

[27] Moisan, M., Ricard, A., Can. J. Phys. 55 (1977) 1010-12.

[28] Pantel, R., Ricard, A., Moisan, M., Distribution radiale de la densité des atomes métastables dans les plasmas produits par un champ électrique continu ou de haute fréquence (Université de Montréal, Physics Dept. and Université Paris-Sud, Plasma Physics Lab : Internal Report) 1982.

[29] Glaude, V. M. M., Moisan, M., Pantel, R., LePrince, P., MareC, J., J. Appl. Phys. 51 (1980) 5693-8.

[30] Chaker, M., Nghiem, P., Bloyet, E., Leprince, Ph., MAREC, J., J. Physique-Lett. 43 (1982) L-71-5. 
[31] Rogers, J., Asmussen, J., IEEE Trans. Plasma Sci. PS-10 (1982) 11-16.

[32] Agdur, B., Kerzar, B., Nygren, T., Phys. Rev. Lett. 10 (1963) 467-8.

[33] Gregory, B. C., Int. Electron. 20 (1966) 495-501.

[34] Brown, S. C., Basic Data of Plasma Physics (Cambridge, Mass : MIT Press) 1961, Sec. 14.4.

[35] Gupta, K. C., Singh, A., Int. J. Electron. 23 (1967) 322.

[36] Hubert, J., Moisan, M., Ricard, A., Spectrochim. Acta 33B (1979) 1.

[37] Moisan, M., Beaudry, C., Bertrand, L., Bloyet, E., GAGne, J. M., Leprince, P., Marec, J., Mitchel, G., Ricard, A., ZaKrzewsKi, Z., IEE Conf. Publication 143 (1976) 382-5 (International Conf. on Gas Discharges, Swansea, UK).

[38] Stangeby, P. C., Daoud, M. A., Can. J. Phys. 53 (1975) 1443-8.

[39] Lisitano, G., Fontanesi, M., Sindoni, E., Appl. Phys. Lett. 16 (1970) 122-4.

[40] Bertrand, L., Monchalin, J. P., Pitre, R., Meyer, M. L., Gagne, J. M., Moisan, M., Rev. Sci. Instrum. 50 (1979) 708-13.

[41] Bertrand, L., Gagne, J. M., Bosisio, R. G., Moisan, M., IEEE Quant. Electron. QE-14 (1978) 8-11.

[42] Locke, J., Anal. Chim. Acta 113 (1980) 3.

[43] Fassel, V. A., Anal. Chem. 51 (1979) 1290A.

[44] BeEnaKKer, C.I.M., Spectrochim. Acta 32B (1977) 173.

[45] Hanai, T., Coulombe, S., Moisan, M., Hubert, J., Developments in Atomic Plasma Spectrochemical
Analysis, R. Barnes editor (London : Heyden) 1981, pp. 337-334.

[46] Chevrier, G., Hanai, T., Tran, K. C., Hubert, J., Can. J. Chem. 60 (1982) 898-903.

[47] Van Dalen, J. P., De Lozenne-Coulander, P. A. De Galan, L., Anal. Chim. Acta 94 (1977) 1.

[48] Estes, S. A., Uden, P. C., Barnes, R., Anal. Chem. 53 (1981) 1829.

[49] Abdallah, M. H., Coulombe, S., Mermet, J. M., Hubert, J., Spectrochim. Acta (in press (1982)).

[50] Henry, D., Hajlaoui, Y., Arnal, Y., Pantel, R., MoISAn, M., An efficient ion source using a surface wave launcher, Conference on surface waves in plasmas, Blagoevgrad, Bulgaria (1981) (Unpublished).

[51] HaJlaOUI, B. Y., Evaluation des performances de divers types de sources d'ions capables de délivrer des faisceaux monocinétiques d'une dizaine de $\mathrm{mA} \grave{a}$ quelques $\mathrm{keV}$ en environnement spatial (3rd cycle doctorate thesis, Université d'Orléans, France) October 1981.

[52] Loncar, G., Musil, J., Bardos, L., Czech. J. Phys. B30 (1980) 688.

[53] Mansfield, J. M. Jr., Bratzel, M. P. Jr., Norgordon, H. O., KNAPP, D. O., ZACHA, K. E., WINEFORDNER, J. D., Spectrochim. Acta 23B (1968) 389-402.

[54] Lebedev, Yu. A., Polak, L. S., Khymiya Vysokikh Energii 13 (1979) 387 [High Energy Chemistry 13 (1979) 331]. 